\title{
An Assessment of Stream Fishing Venues in West Virginia: A Comparison of Anglers along a Spectrum of Access
}

\author{
Radley E. Miller \\ West Virginia University
}

Follow this and additional works at: https://researchrepository.wvu.edu/etd

\section{Recommended Citation}

Miller, Radley E., "An Assessment of Stream Fishing Venues in West Virginia: A Comparison of Anglers along a Spectrum of Access" (2012). Graduate Theses, Dissertations, and Problem Reports. 3535. https://researchrepository.wvu.edu/etd/3535

This Thesis is protected by copyright and/or related rights. It has been brought to you by the The Research Repository @ WVU with permission from the rights-holder(s). You are free to use this Thesis in any way that is permitted by the copyright and related rights legislation that applies to your use. For other uses you must obtain permission from the rights-holder(s) directly, unless additional rights are indicated by a Creative Commons license in the record and/ or on the work itself. This Thesis has been accepted for inclusion in WVU Graduate Theses, Dissertations, and Problem Reports collection by an authorized administrator of The Research Repository @ WVU. For more information, please contact researchrepository@mail.wvu.edu. 


\title{
An Assessment of Stream Fishing Venues in West Virginia: A Comparison of Anglers along a Spectrum of Access
}

\author{
Radley E. Miller
}

Thesis submitted to the

Davis College of Agriculture, Natural Resources and Design

at West Virginia University

in partial fulfillment of the requirements

for the degree of

Master of Science

in

Recreation, Parks, and Tourism Resources

Chad D. Pierskalla, Ph.D., Chair

Robert C. Burns, Ph.D.

Alan R. Collins, Ph.D.

Department of Recreation, Parks, and Tourism Resources

\author{
Morgantown, West Virginia
}

2012

Keywords:

Recreational Stream Angling, Social Carrying Capacity, Normative Theory 


\title{
ABSTRACT \\ An Assessment of Stream Fishing Venues in West Virginia: A Comparison of Anglers along a Spectrum of Access
}

\author{
Radley E. Miller
}

\begin{abstract}
West Virginia places an emphasis on fishing as a way to increase nature-based tourism. However, heavy fishing pressure on public water and unequal fishing effort at stocking locations can lead to declining catch rates and an increasing number of visitors that experience catch deprivation and dissatisfaction. Controlling access to streams is one approach to dealing with this carrying capacity issue. Both public and private land managers have approached this problem differently using various levels of control. For example, Pipestem State Park managers provided anglers with access to the Bluestone River with few controls via an aerial tramway prior to 2009. In recent years, the park has controlled access by stocking trout at the beginning of the shoulder season (November-April) when the tram is closed, thus limiting access to the river via a strenuous 4 mile hike on steep terrain. At Harman's North Fork Cottages, access is controlled on private land. Only guests that stay in the luxury log cabins are given easy and nearby access to a stocked segment of river. The purpose of this study is to compare the success, satisfaction, and perceived crowding of four stream fishing venues that fall along a spectrum of access from completely open access to closed, invitation only access. A total of 154 adult anglers completed an on-site interview. Indicators of fishing success (e.g., Catch Per Unit Effort) and economic impact of stocking strategies will be compared among the fishing venues. Catch Per Unit Effort values were found to be significantly different from one venue to another, while acceptability of catch was found not to be. The catch rate normative curve developed from this information is included, which shows the preferred and minimally acceptable catch rates for each different fishing venue. Additionally, significant differences were found in the number of anglers observed fishing on the stream by other anglers is reported, as it addresses the issue of perceived crowding and social carrying capacity.
\end{abstract}




\section{ACKNOWLEDGEMENTS}

Throughout my two years at West Virginia University, I cannot be more thankful to have such a supportive and helpful committee chair and advisor. I would first like to thank Dr. Chad Pierskalla for his never ending support, guidance, and drive for me to complete this thesis. It has been under his guidance that I have been so fortunate to excel during my time here at WVU.

A special thank you also goes out to both Dr. Robert Burns and Dr. Alan Collins who both have served on my thesis committee to further support and steer my efforts throughout this process.

I would also like to thank the USDA Aquaculture Development Grant for funding this project and myself, and providing me the opportunity to work cooperatively with not only my committee on aquaculture based research, but also with Dr. Ken Semmens and Dr. Cyril Logar. Also supporting my thesis work are the management and staff of Pipestem State Park Resort as well as the Harman and Roby family that allowed me to collect data at their property, Harman's North Fork Cottages.

I would also like to thank the other professors at WVU that have assisted me in my pursuit of knowledge. Drs. Steve Selin, Jingyang Deng, Kudzayi Muambe, Michael Strager, Trevor Harris, Gerald Hobbs, and Timothy Warner I cannot thank you enough for all that you taught me in the past two years. While I was not fortunate enough to have any in class education, I would also like to thank Dr. Dave Smaldone for his support as well as Dr. Nicolas and Sera Zegre for their support both inside and outside of Percival Hall.

Additionally, there is long list of my fellow graduate students whom I have had the pleasure of meeting while at WVU whom all have helped me progress, improve, or learn in some way. For all of you, thank you for being there.

To my parents, Jeffrey and Christine Miller, it is impossible for me to say thank you enough for all you have done for me. I am so fortunate to have parents that supported me and had faith in me no matter what.

To my sister Rebecca Miller, I thank you for all of your support. I hope to see you reach your dreams, whatever they may be.

I also cannot thank my grandmother Anna Mae Miller enough for the support she has given me through all of life's adventures, as well as my grandfather, Willard Talley. Your support is what keeps the focus and drive alive when it came down to completing this thesis.

Finally, I'd like to thank the paddling community in West Virginia for welcoming me, mentoring me, and providing me with a family outside of my own.

To everyone that I have met at WVU in the past two years, thank you all! 


\section{TABLE OF CONTENTS}

page

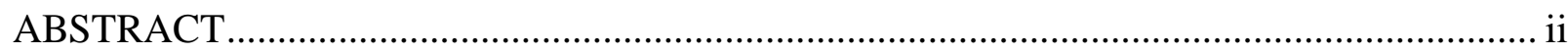

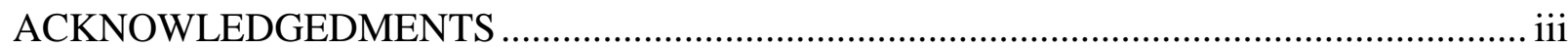

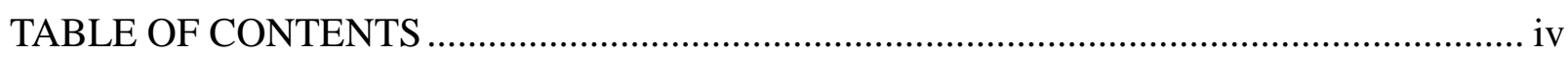

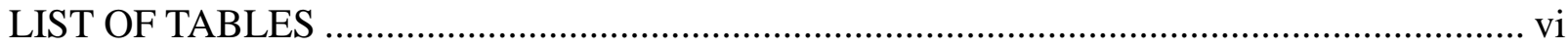

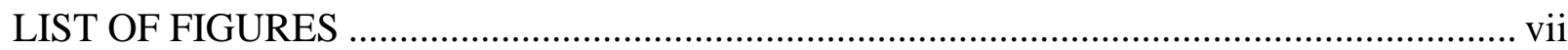

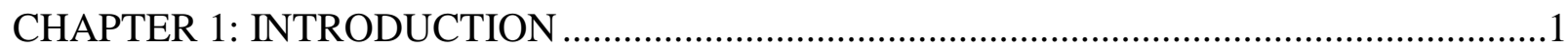

Background to the Research Problem...............................................................

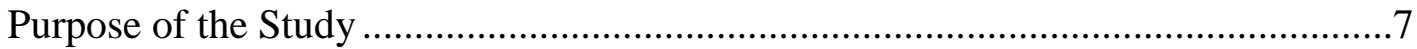

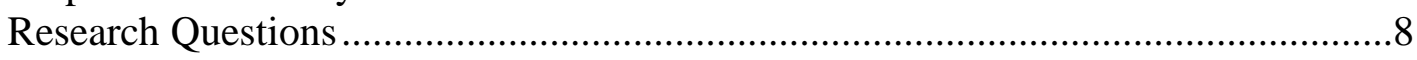

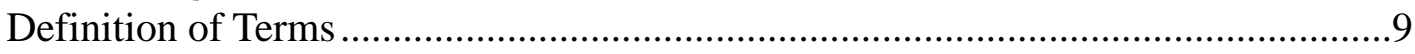

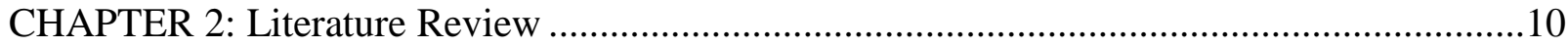

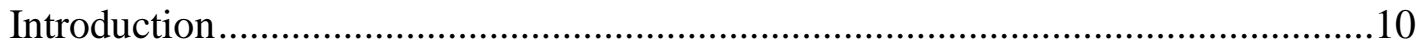

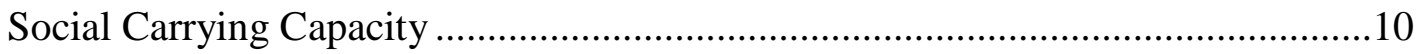

Normative Approach ........................................................................... 11

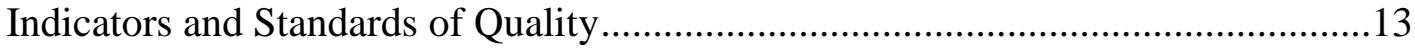

Catch Related Factors of Quality Fishing Experiences .......................................14

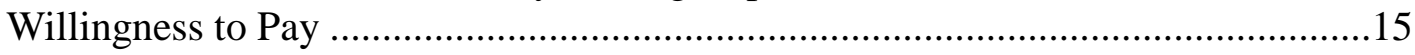

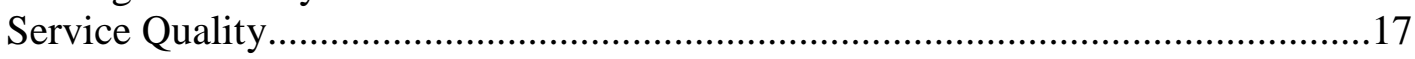

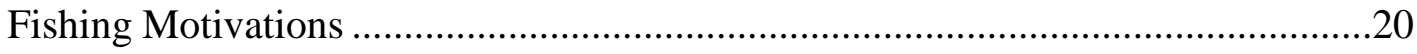

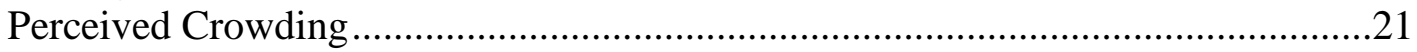

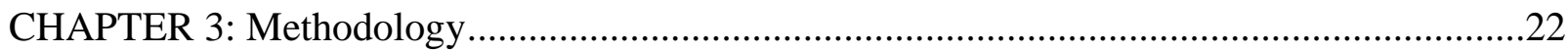

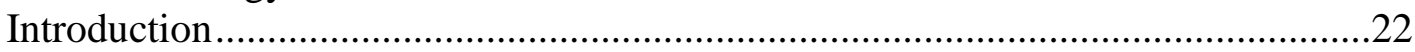

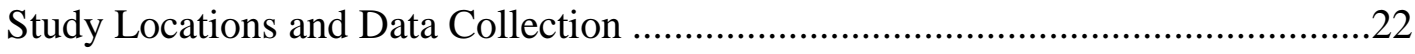

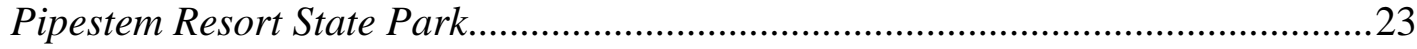

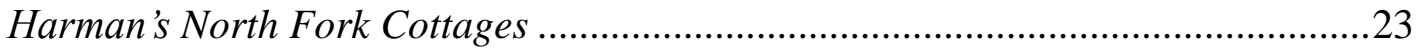

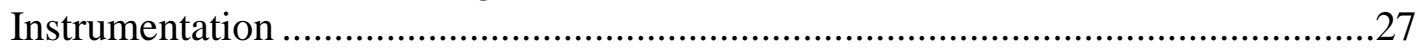

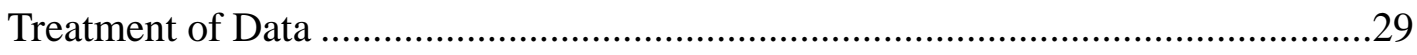

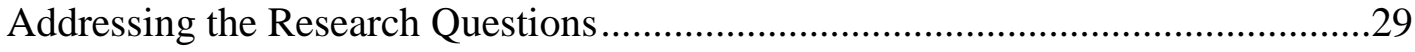

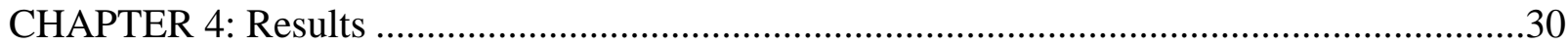

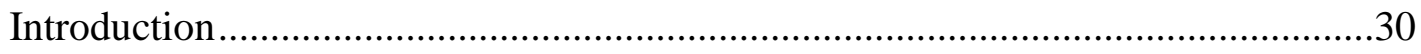

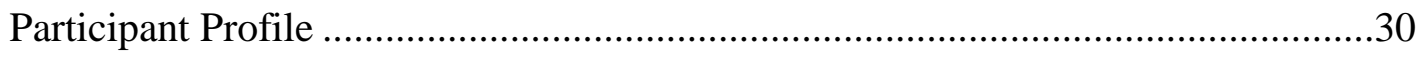

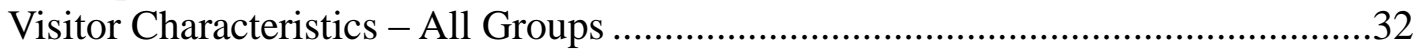

Visitor Characteristics - Open Access Anglers .................................................... 33

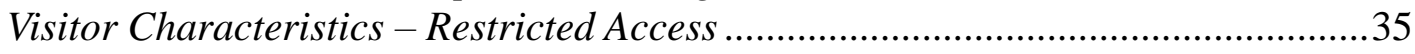


Catch Related Factors of Quality Fishing Experiences .......................................38

Yearly Fishing Equipment Expenditures ..........................................................43

Comparing Variables Associated with Quality Fishing Experiences.......................44

Analysis of Other Anglers, Crowding, and Influence on Satisfaction .....................50

Regression Model for Catch Per Unit Effort .................................................50

CHAPTER 5: Discussion, Conclusion, and Recommendations ......................................52

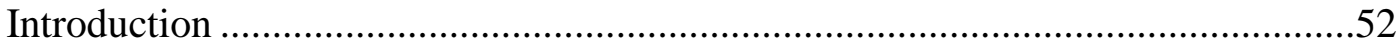

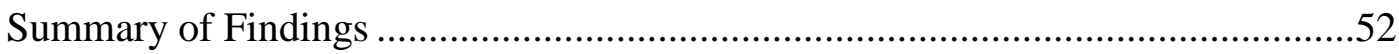

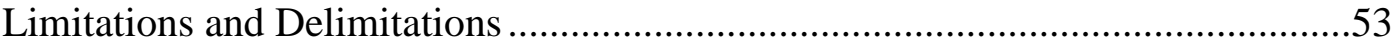

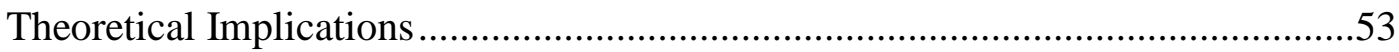

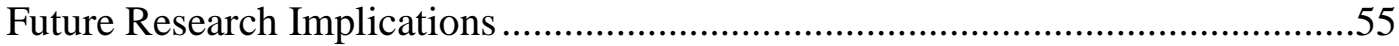

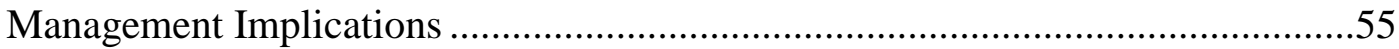

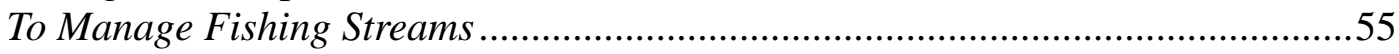

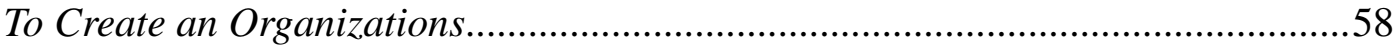

APPENDIX I: Pipestem Resort Survey Instrument......................................................60

APPENDIX II: Harman's North Fork Cottage's Survey Instrument...................................64

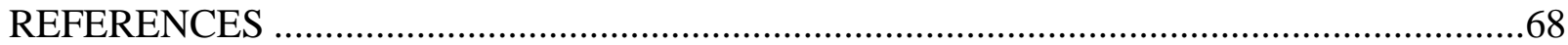




\section{LIST OF TABLES}

page

TABLE 1. On-site Interview Response Rate 30

TABLE 2. Total Sample Size 30

TABLE 3. Survey Instruments Collected per by Fishing Venue 31

TABLE 4. Visitor Characteristics (Gender, Marital Status) 32

TABLE 5. Visitor Characteristics (Annual Income, Race) 32

TABLE 6. Visitor Characteristics (Age, Distance Traveled) 33

TABLE 7. Angler Use History 33

TABLE 8. Visitor Characteristics (Gender, Marital Status) Open Access 34

TABLE 9. Visitor Characteristics (Annual Income, Race) Open Access 34

TABLE 10. Visitor Characteristics (Age, Distance Traveled) Open Access 35

TABLE 11. Angler Use History Open Access 35

TABLE 12. Visitor Characteristics (Gender, Marital Status) Restricted Access 36

TABLE 13. Visitor Characteristics (Annual Income, Race) Restricted Access 37

TABLE 14. Angler Use History and Activity Specialization--Restricted Access 37

TABLE 15. Visitor Characteristics (Age, Distance Traveled) Restricted Access 37

TABLE 16. Catch Related Factors of Quality of Fishing Experience 38

TABLE 17. Catch Related Factors Open Access 39

TABLE 18. Catch Related Factors Open Access Unguided Anglers 39

TABLE 19. Catch Related Factors Open Access Guided Anglers 40

TABLE 20. Catch Related Factors Restricted Access 41

TABLE 21. Minutes Spent Angling 42

TABLE 22. Minutes Spent Angling - Open Access 42

TABLE 23. Catch Per Unit Effort -- Venue 43

TABLE 24. Catch Per Unit Effort -- Groups 43

TABLE 25. Expenditures on Gear Annually (USD\$) 44

TABLE 26. ANOVA of Catch Related Factors by Fishing Venue 46

TABLE 27. ANOVA Other Measures of Catch Success by Fishing Venue 47

TABLE 28. ANOVA Table on Site Visitation and Motivation 49

TABLE 29. ANOVA Table on Perceptions of Crowding by Fishing Venue 50

TABLE 30. Regression Estimates for Prediction of Catch Success (CPUE) 51 


\section{LIST OF FIGURES}

Figure 1. Study Site Locations

Figure 2. Guided angler on public land with his catch 4

Figure 3. Guided angler on public land landing in a fish 5

Figure 4. Tournament angler fishing on private land 6

Figure 5. Normative Curve for Angling 12

Figure 6. Horses and Tram - Access to Bluestone River Gorge in Pipestem State Park 25

Figure 7. A Guide Instructing Guests at Pipestem Resort 25

Figure 8. An Angler Fishes at Harman's North Fork Cottages 26

Figure 9. Tournament Spectators at Harman's North Fork Cottages 26

Figure 10. Tournament Anglers Completing Survey at Harman's North Fork Cottages 28

Figure 11. Development of Catch Rate (CPUE) Acceptability Normative Curve 49 


\section{CHAPTER 1 \\ INTRODUCTION}

\section{Background to the Problem}

Hardin (1968) published the famed "Tragedy of the Commons" paper. This article led to an entire body of literature which seeks to explain what happens to a finite public resource when limitations and restrictions are not set. In his paper, the unrestricted use of a public pasture is used to describe the situation. Private entities exist to benefit from this resource by grazing their cattle on this land. Because it is public and open to all for use, if an individual chooses to add an additional cattle to the property, their net benefit is plus one cattle, as there is no cost that exists for them to do so. Since all additional cattle are net benefits to each producer using the land, higher benefits are received from exploitation of this common property (i.e., more cattle are added). When in reality, there is a cost associated with each additional animal added, but the costs are not incurred by the individual directly. The costs are shared by all participants in the public pasture, and the common resource is degraded over time. These compounded externalities of misuse of common property result in a decreased value of that pasture because of the poor management of a resource for personal gain.

These externalities can be both positive and negative; however in the tragedy of the commons they are primarily negative. In any instance where a public good or service exists, there is the possibility for a situation to arise as described by Hardin. Instead of a cow pasture open to all, imagine public stream fishing access within the state of West Virginia. This stream contains a reward, the fish, for those individuals seeking to exploit the stream's resources through fishing. With only a few anglers fishing occasionally along the stream, conflicts and issues are nil because of the streams ability to satisfy the needs of those anglers. As additional anglers enter the stream to fish, minimal impacts are felt by the other anglers because the impacts are 
shared by the total number of anglers fishing a portion of stream. However, the stream, just as the cow pasture or any other resource, is finite. When at first the impacts of the other fisherman were not felt do to the seemingly infinite resources within the stream, now as additional anglers begin to fish, the finite nature of the stream is exposed.

At a point, the recreational benefits that anglers realize from fishing a stream are negatively affected and the fishing experience may become unacceptable. The stream reaches its carrying capacity at this point. This carrying capacity is the maximum number of individuals that attain satisfactory fishing experiences from a finite resource. Carrying capacity becomes an issue when the number of individuals seeking fishing opportunities is greater than the carrying capacity of the streams.

Through the management and understanding of the carrying capacity of the commons, the necessary steps are in place in preventing the occurrence of the tragedy of the commons (Manning, 2010). There then creates a need for fee fishing destinations within West Virginia to reduce the fishing pressure on public waters. If the resource is finite and cannot increase beyond a maximum threshold to handle the ever increasing demand of these resources, limits to access are required. In the case of a common pasture stream access, degradation is noticeable and losses are incurred after significant increases in the number of anglers fishing the stream. By creating restrictions, such as limiting the number of anglers, creating an upfront cost for access, or the two used in combination creates a situation where choices must be made whether or not to use the restricted resource. With the correctly applied measures, the number and type of user will be managed at or below carrying capacity.

Fee fishing destinations within the state present challenges to managers and their use of carrying capacity decision-making frameworks. Figure 1 shows the locations of both study sites 
within the state of West Virginia. The gradient of restrictive management actions can be seen depending on the season or location that is visited. The Pipestem Resort State Park and its Bluestone River provide different examples of how recreation access can be restricted. The gorge is a resource that is not easily accessible, but seasonally the park operates a tram that transports guests down into the canyon to fish the waters and enjoy other activities. Year round anglers can fish the Bluestone River, but these restrictions create new seasonal tourism markets within the park. In times when the tram is non-operational, the angler must hike into the canyon to access the stream. Overnight lodging opportunities with included guide service, meals, and transportation to the stream side lodge are offered during these times providing, at a cost to the angler, access to the Bluestone River. Figures 2 and 3 depict the opportunities provided within Pipestem Resort. With these restrictions in place, those anglers willing to pay the fee to participate in a stream fishing experience will do so with limited interruption and competition from other anglers. The situation at Pipestem State Park is not strictly controlled stream access, but instead it is a gradient of limitations that are managed to avoid some of the problems associated with open access and the tragedy of the commons from occurring.

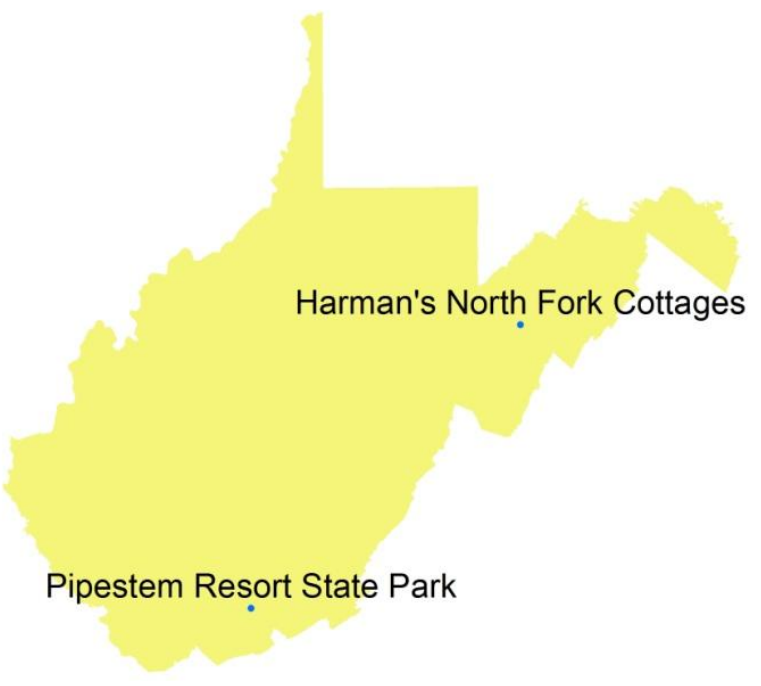

Figure 1. Study Site Locations 


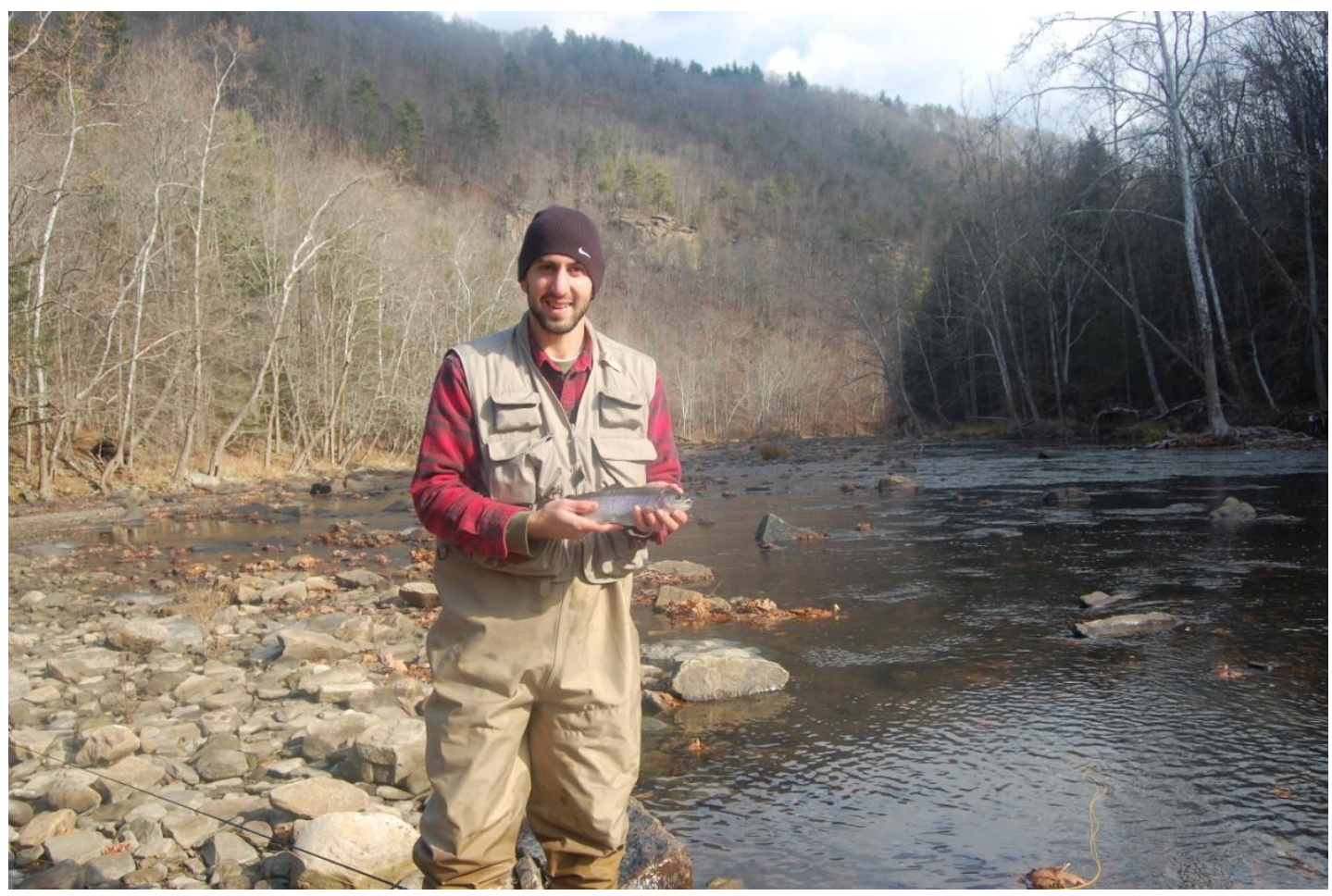

Figure 2. Guided angler on public land with his catch

Extreme access restrictions create a unique situation, where the land owner or organization manages the property for a limited number of users. With Harman's North Fork Cottages, a property that provides access to several miles of trophy trout fishing along the North Fork of the South Branch of the Potomac, is the example of a highly restrictive access to a resource. Only those who purchase lodging at the resort are allowed to fish the property during their stay. This limits the total number of anglers on the stream to the total occupancy of the resort. By doing so, this creates a selective few who have the rights to consume this private property and avoid the tragedies associated with common property. 


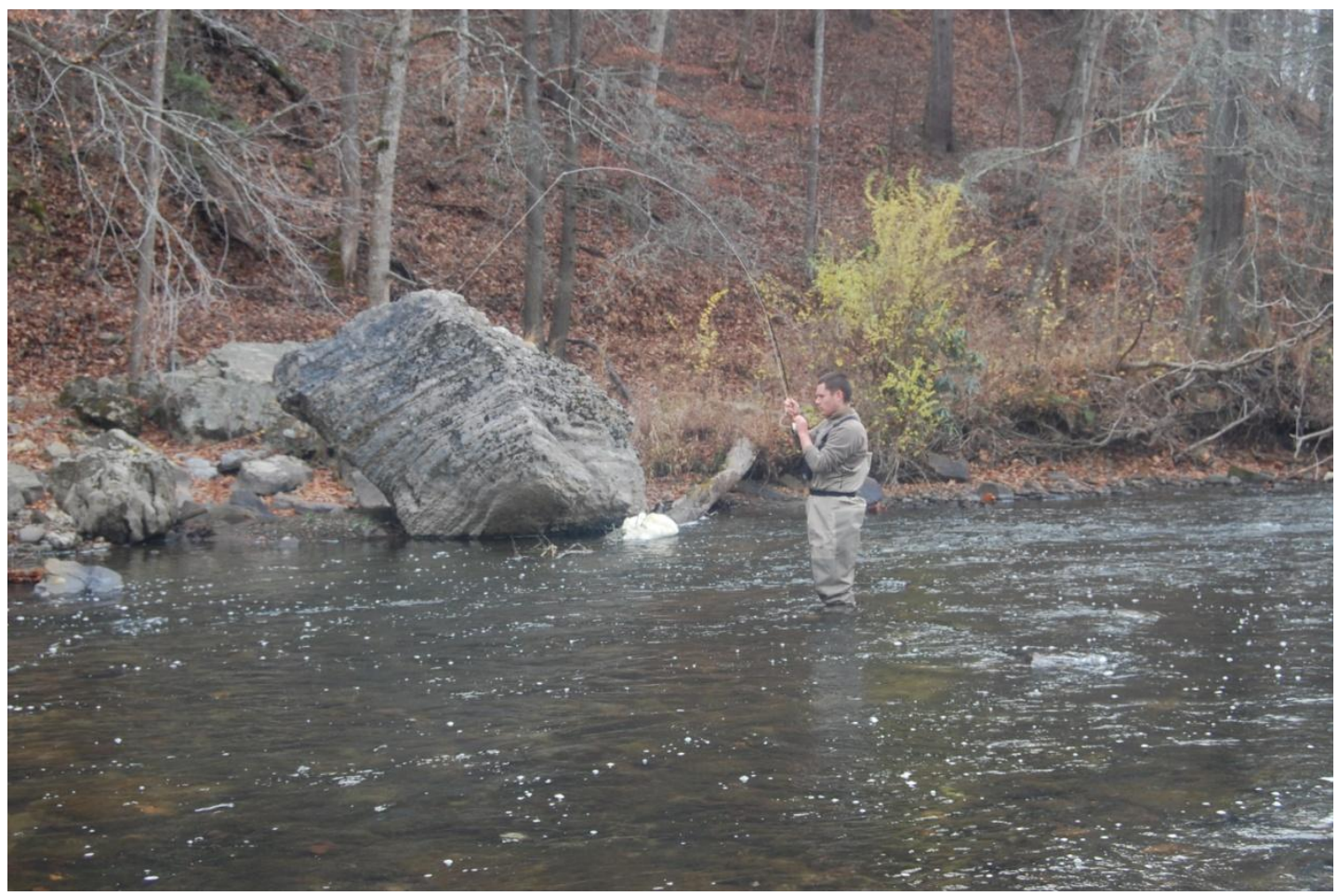

Figure 3. Guided angler on public land landing in a fish

Limitations and restrictions must be applied through management to avoid overuse and the tragedy of the commons. Creel surveys can be conducted to understand and quantify the catch related factors and experiences that are realized by visitors of streams such as the Bluestone River and North Fork of the South Branch of the Potomac River. In those situations, the managers of the property are not looking to restrict access to maintain an ecological balance, but instead seek to manage the number of anglers accessing the stream so that the quality of visitor experience is acceptable. Figure 4 depicts the situation at Harman's North Fork Cottages, and the opportunities provided by managers.

The property rights also present a unique problem. Water resources are treated differently than land resources in terms of property rights. In a study of private land ownership at a trophy hunting area instead of a trophy fishing area the "boundaries" would have a much clearer definition (e.g., fences). The rights bestowed upon the land owner extend to all parts of the 
property for their control and benefit. However, the property rights of stream and streambed access can vary. For instance, Virginia residents can claim the streambed as their property and therefore prohibit wading anglers from fishing on any section of stream that crosses their property. In West Virginia, and many other states, the streambed is considered public property and opens to all. When managers stock a privately accessed stream with fish, the areas where the stream enters and leave the property are access points in which access to these fishing resources can be obtained by other anglers. Although it would be trespassing for them to walk along the banks of the river, wading from a public access stream up to the property is legal under these definitions. Restricting access is a method that can be used to deal with the tragedy of the commons; however, this property rights issue makes it more difficult for land managers to protect their stocking investments from non-paying visitors. What is important to understand in these cases is the importance of controls or restrictions on the angling experience.

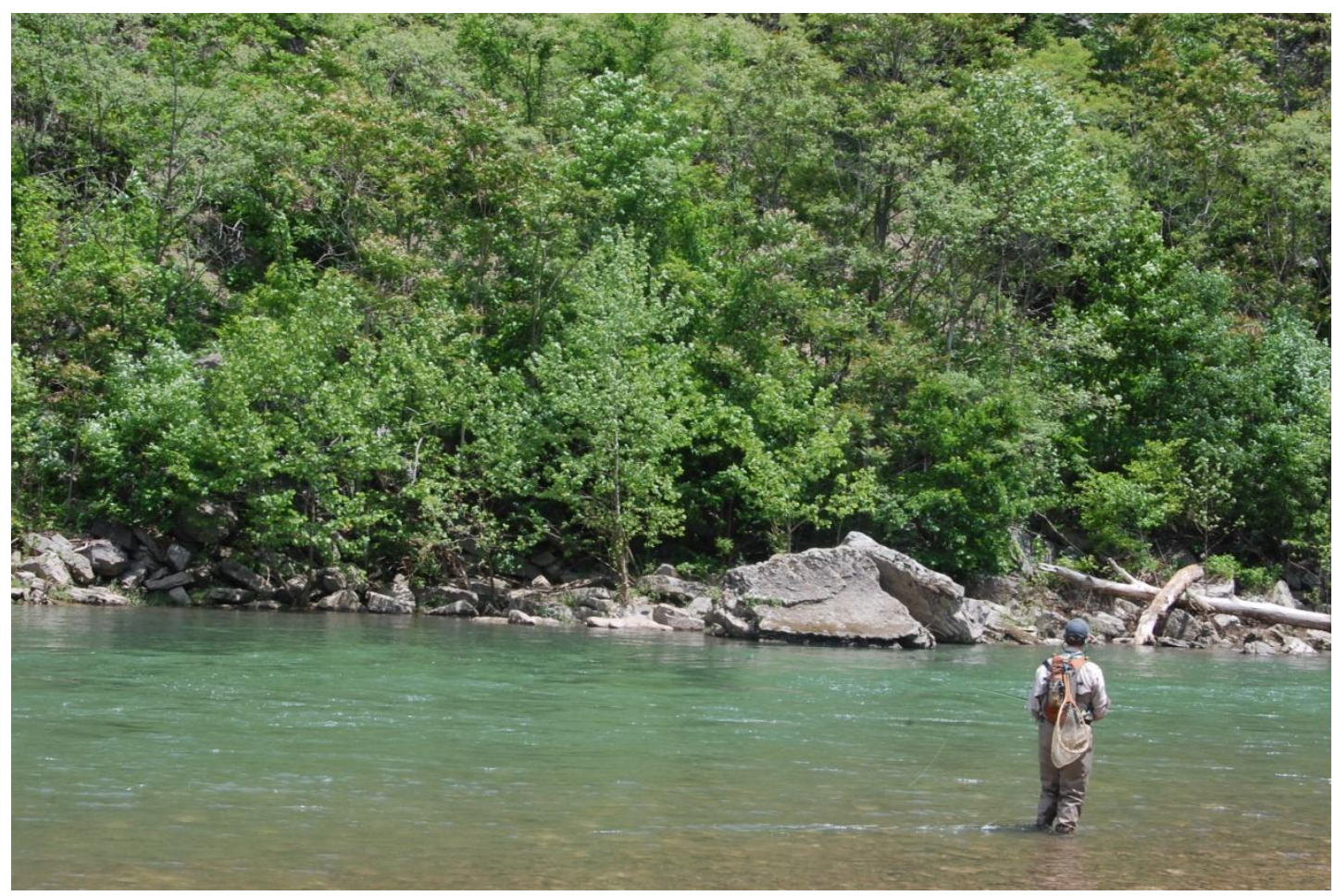

Figure 4. Tournament angler fishing on private land 


\section{Purpose of the Study}

The purpose of this study is to compare fishing success and catch-related norms, satisfaction, and perceived crowding of four stream fishing venues that fall along a spectrum of access from open access on public lands to closed, invitation only access on private lands. Harman's North Fork Cottages (HNFC) hosts trophy trout fishing and luxury log cabin rentals for guests. Harman's provides trophy rainbow trout fishing on a five mile section of privately stocked stream on the North Fork of the South Branch of the Potomac River. The goal of this study is to identify indicators and standards of quality for fee fishing venues, as well as better understand the motivations, willingness to pay, and demographics of the visitors to Harman's Cabins and the Bluestone River in Pipestem State Park. Harman's provides a unique experience to its clients by stocking quality fish in the stream from the anglers as well as limiting the number of anglers fishing the stream. The small segment of the Bluestone River located in Pipestem State Park also offered two unique fishing opportunities (open access and fishing packages) that are useful benchmarks along a spectrum of access. 


\section{Research Questions}

The following research questions were proposed for 4 fishing venues (Open Access-

Unguided Anglers at Pipestem Resort; Open Access Guided Anglers at Pipestem Resort;

Restricted Access-Unguided Anglers at Harman's North Fork Cottages; Restricted Access-

Tournament Anglers at Harman's North Fork Cottages.):

$\mathrm{R}_{1}$ : What are the visitor characteristics of the four different fishing venues?

$\mathrm{R}_{2}$ : How do catch-related factors of quality differ by fishing venues?

$\mathrm{R}_{3}$ : What are the ranges of acceptable catch-rates (including preferred and minimum acceptable condition) for the fishing venues?

$\mathrm{R}_{4}$ : How does overall quality of the fishing experience and willingness to pay differ among the fishing venues?

$\mathrm{R}_{5}$ : What relationships exist between access, age, gender, site visitation, and annual angling expenses as they relate to catch rates? 


\section{Definition of Terms}

Catch-deprivation. When an individual angler catches a lesser number, species, or size of fish than desired (Finn \& Loomis, 2001).

Catch-satisfaction. When an individual angler catches the desired number, species, or size of fish (Finn \& Loomis, 2001).

Catch Per Unit Effort. Defined as the total catch divided by the total quantifiable effort put forth for the catch and is generally associated with time, but may be spatially or with other strata (Maunder et al., 2006)

Catch and release. Defined as returned a fish to the body of water that it was caught from after angling

Fee-fishing. A subactivity of fishing; the act of paying for the privilege to access a private pond or stream to fish for artificially enhanced fish populations through stocking (Cichara, 1982.)

Service quality. The comparison made by customers between the expectations held and the perceived service that is received (Gronroos, 1982; Parasaman et al., 1985, 1988; Burns, 2000; Burns et al., 2003). 


\section{CHAPTER 2 \\ LITERATURE REVIEW}

\section{$\underline{\text { Introduction }}$}

The purpose of this chapter is to review the relevant literature as it pertains to the evaluation of four fishing venues in WV. The Normative Approach to defining Social Carrying Capacity is the conceptual framework of this study and is discussed first. Additional literature is presented to better understand the other variables (i.e., overall fishing experience, fishing motivation, crowding, and willingness to pay) that were measured in this study.

\section{Social Carrying Capacity}

Understanding carrying capacity of a resource is critical to averting a tragedy of the commons for that given resource. First defined by Dasman (1964), carrying capacity was defined as the number of species a given habitat can support sustainably, and then was conceptualized by Wagar (1964) for use in parks and recreational settings. In his writing, he theorized that as the number of individuals visiting a recreation site increased, not only did the effects upon the environment increase but the visitor experience was negatively impacted.

A multitude of literature exists on the application of carrying capacity in parks and recreations settings; however, the success of these efforts is limited. This research has indicated that as use of parks and recreational areas increase, the impacts to the environment also increase. These impacts include, but are not limited to: soil compaction and erosion, vegetation trampling, water pollution, and wildlife disturbance. Increasing numbers also have effects on the recreational experience, such as aesthetics, overall quality, crowding, and conflict within the resource (Manning, 1999, 2010; Manning \& Lime, 2000).

Management of carrying capacity should fall into three broad categories. The resource is the natural environment in which the recreational activity is taking place. Understanding the 
impacts and acceptable levels of change are important in managing the resource. Considerations must be undertaken as some resources are resilient, others may be quite fragile and management should akin to a variety of resources. Secondly, the experiential facet of managing the resource must be taken into account. This involves the overall experience of the visitor as they recreate at the given site. Monitoring through surveys creates input from users that then can influence managerial and social aspects of the experience. Lastly, management is the third category involving directives and policies that exist to maintain the resource and experience within certain management objectives and standards. Multiple carrying capacity frameworks have been developed to incorporate these three categories into a working management plan for carrying capacity of a given park or outdoor recreation venue (Manning, 2010).

\section{Normative Approach}

The Normative Approach, based on the constructs of norms or the normal condition is the conceptual framework for this thesis. Norms are applied in sociology as to what is expected to be normal behavior or normal interactions between individuals. They differ from attitudes. Attitudes can be either positive or negative. Norms are standards and determine what conditions ought to exist or what is acceptable (Manning, 2010). Normative theory development has come through three branches (Vaske \& Whittaker, 2004). Work by Cialidini, Reno, and Kallgren (1990) and Cialidinia, Kalgren, and Reno (1991) examine the variables that address these norms and bring those variables into focus. The second branch of normative theory, focuses on how attitudes and norms impact user behavior (Azjen \& Fishbien, 1980; Fishbien \& Azjen, 1975). The third branch worked on developing the return potential model, which focuses on the application of carrying capacity and other structural models into social norms (Jackson, 1965).

Work by Jackson (1965) in normative theory involved survey methods to identify the 
range of acceptability of indicators. Responses were collected from users, managers, or employees, and norm curves were created from the aggregated data. Figure 5 displays a hypothesized norm curve for catch related stream fishing factors. Along this curve, the minimally acceptable condition for a catch related indicator is found at intersection of the curve along the zero point of the acceptability scale. Conditions that fall below a level of zero on the acceptability scale are considered to be unacceptable and all conditions above this line are considered to be within the range of acceptable conditions. The preferred condition is the point along the curve that maximum acceptability is reached, and it is at this high level of acceptability that can be used to define a premium stream fishing experiences opportunity.

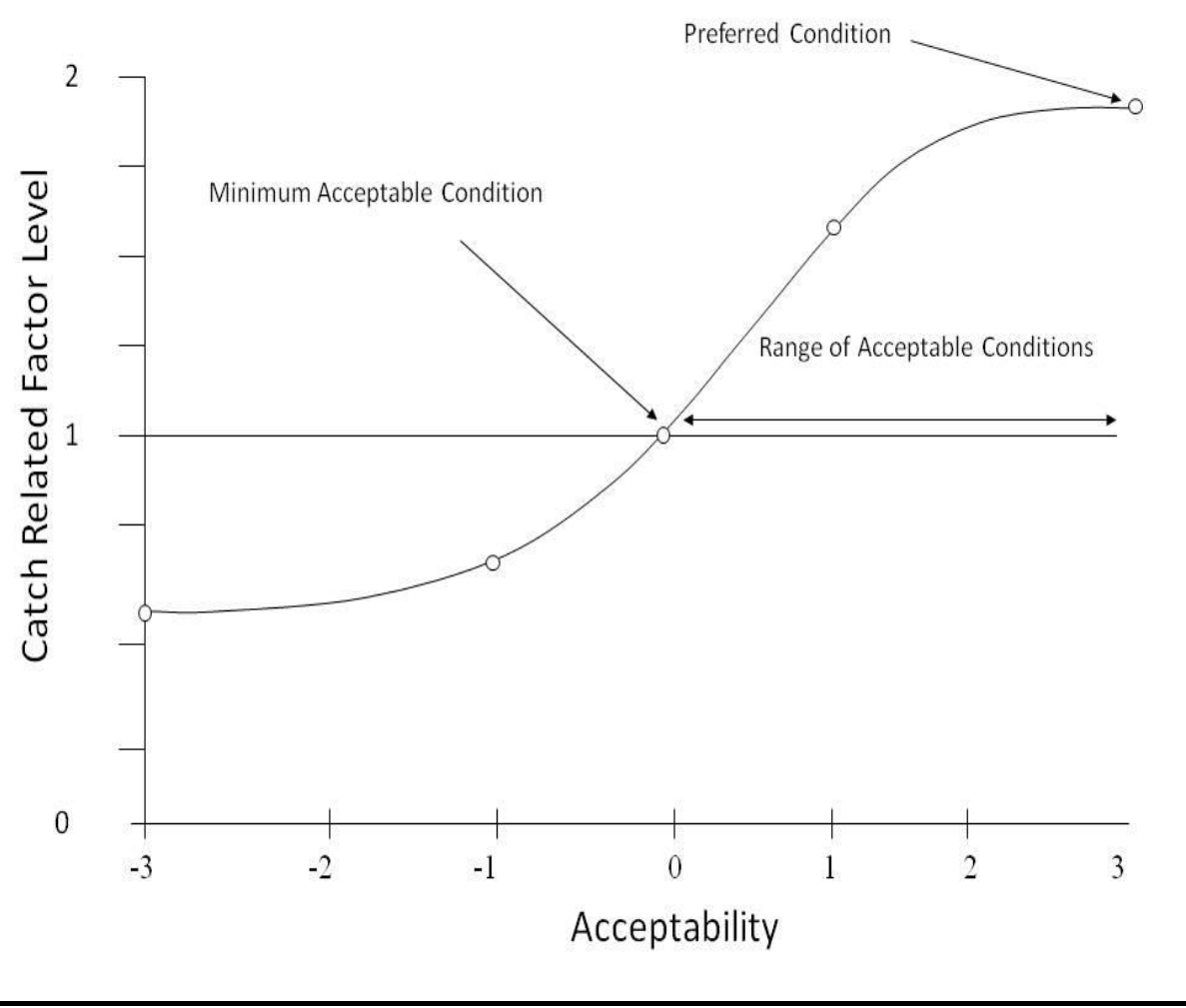

Figure 5. Normative Curve for Angling 


\section{Indicators and Standards of Quality}

Manning (2000) defined indicators as the measurable, manageable variables that help define the quality of parks and outdoor recreation areas (p. 28). Along with indicators, he has defined standards as the minimum acceptable condition of indicator variables (p. 32). There are several criteria that these indicators must meet to qualify as well written indicators. According to Manning (2010) and others, these indicators must be specific, objective, reliable, related to visitor use, sensitive, manageable, efficient, integrative or synthetic, and significant. In the case of recreational fishing studies, the factors of quality fishing experiences often require more specificity to qualify as well written indicators. Indicators are also site specific and need to accurately represent the study area to meet Manning's criteria. For example, "catching a fish" is a factor of quality that lacks specificity. Instead, Catch-per-Unit-Effort (CPUE) defined by Maunder et al. (2006) is a specific and useful indicator of a quality experience that can be managed; and therefore, it meets important criteria of a well written indicator. Manning indicates that a growing body of literature has developed amongst choosing these indicators of quality due to their importance as well as value. Much has been learned about the value of different indicators. It is possible that statistically, some indicators may be of more salient due to the preferences of the users. Manning et al. (2000) found that the types of encounters can be a more valuable indicator than total number of encounters with other users. Specifically, even with a high CPUE, dissatisfaction could occur due to the number of "non-target species caught during the experience.

Standards of quality are defined as measures of several indicators combined to simplify management. Much of the framework of the normative curve has been adapted to develop standards of quality. Well written standards of quality must be: quantitative, time or space 
bounded, expressed as a probability, impact oriented, and realistic.(Brunson et al., 1997;

Manning, 2000; Schomaker, 1984; and Whittaker \& Shelby, 1992).

\section{Catch Related Factors of Quality Fishing Experiences}

West Virginia places an emphasis on fishing as a way to increase the impact of nature-

based tourism on the state's economy. However, heavy fishing pressure on public water (due to population growth, urban expansion, and truck following) and unequal fishing effort at stocking locations can lead to declining catch rates and an increasing number of visitors that experience catch deprivation and dissatisfaction (Radomski, Grant, Jacobson, \& Cook, 2001). For example, a typical goal for trout catch rates on public waters can range between 0.25 trout/angler-hour to 0.7 trout/angler-hour (Miko, Schramm, Arey, Dennis, \& Mathews, 1995), yet a mean catch rate considered to be successful by those anglers is often much higher (e.g., 1.44 trout/angler-hour) (Miko et al., 1995). In a study conducted by Moldovanyi, Pierskalla, and Schuett (2005), results indicated that the ideal catch rate on private waters in West Virginia is 5 trout per daily visit. Finn and Loomis (2001) also reported that the importance attached to catch motives increases as success in catching a preferred fish decreases. The numbers of anglers that experience catch deprivation may be on the increase considering the growing fishing pressure placed on a fixed supply of public waters.

One approach to dealing with declining catch rates has been to allow non-governmental organizations to supplement governmental efforts in the provision of more stocked fish (Rosenberger, Collins, \& Svetlik, 2005). The results of their study indicate that anglers are generally supportive of the program. However, stocking higher numbers of fish does not always result in higher angler catch rates, unless access to the area is controlled (Butler \& Borgeson, 1965). 
There are many different factors that influence the satisfaction and enjoyment of fishing activities. One that is very important in the catch-per-unit effort (CPUE). The CPUE is calculated by totaling the catch and dividing it by the effort put forth by the fisherman. Generally the effort is measured temporally, but it can also be measured spatially or by other means (Maunder et al, 2006). What is important with fee fishing areas is to provide adequate fish for the visitors to catch while they are visiting the property to increase overall satisfaction. Stocking fish in the stream achieves this goal but also must be managed correctly. Understanding the CPUE allows managers to efficiently stock fish for both the enjoyment of their guests and economically for their budgets.

Other than their catch rates, there are other factors that affect the overall experience and fishing satisfaction. Graefe (1986) conducted a study on recreation saltwater fisherman in Delaware and Maryland and found several factors that influence the experience. Factors that were discussed were the number of other fisherman, or crowding, not catching the desired number of fish, and situational factors. While standards of quality must be repeatable, manageable items this excludes some situational issues that arise during the fishing experience (Manning, 2010). However, the crowding issue in the realm of fee fishing can be dealt with as the manager can control the fisherman density on their property through capping. Crowding is the culprit in the carrying capacity issue, specifically in the realm of the open access which can cause catch deprivation as competition increases to a critical point that reduces satisfaction.

\section{Willingness to Pay}

Willingness to pay (WTP) reflects the participants' additional perceived value of their experience. Fields et al. (2004) examined anglers'WTP for the opportunity to fish for a new species - hybrid bluegill. The study was conducted at three West Virginia pay fishing businesses. 
The result shows that anglers are willing to pay about $\$ 30$ per 10 fish for catch-and-keep, or \$29 per 1 hour for catch-and-release fishing opportunities are similar. Rosenberger et al. (2005) examined anglers' WTP for a trout stocking program for Cheat River, WV. The authors found that WTP increases with respondent dissatisfaction with last year's fishing experience, importance of catching a lot of fish, keeping fish after catching them, and the respondent's age, education, and income level. WTP declined among respondents who were not supportive of the stocking program and resided further from the stocking site. Estimated average per-trip mean and median WTP were $\$ 4.60$ and $\$ 3.36$, respectively. Cantrell et al. (2004) estimated anglers' WTP for increased catch rate resulting from a stock enhancement program for Pacific threadfin in Hawaii. Recreational anglers were willing to pay an average $\$ 7.95$ to maintain their current catch level of 3.8 Pacific threadfin per fishing trip. They were willing to pay an even higher amount of $\$ 10.05, \$ 13.67, \$ 19.95$, or $\$ 20.52$ to increase their average catch by $1,3,9$, or 11 Pacific threadfin per fishing trip respectively. The authors found that employment status, occupation, and income were the variables that affected individual WTP at statistically significant levels. Similarly, Johnson and Walsh (1987) used CV to estimate the value of fish caught at Colorado's Blue Mesa Reservoir, and reported the value of additional trout or coho salmon caught at the site to approximately equal \$0.95. Johnson and Walsh (1989) examined anglers' WTP on the Poudre River and found that the mean catch was four fish per angler day and the value of catching an additional fish was approximately $\$ 0.78$

On the North Branch of the Potomac River, surveyed recreationalists in both angling and boating were found to be willing to pay close to $\$ 4.1$ million dollars extra per year to secure the quality of the resource. Local anglers had a mean WTP of $\$ 383$ dollars per user day, visiting anglers had a mean WTP of $\$ 263$ per user day, and boaters had a WTP of $\$ 59$ dollars per day. It 
was determined that the resources of the North Branch of the Potomac River had been severely undervalued, and the willingness to pay for access, improvement, and protections to the river by recreationalists is at a level that can provide long term financial support for the water based recreational activities. Investment in the protection of the watershed is important as the WTP for the access as the return on the investment in quality stream access would be significant compared to the investments needed to maintain the water quality and stream fishing habitat (Hansen, Collins, Zegre, \& Hereford, 2010).

\section{Service Quality}

With the increasing proportion of the American economy leaning towards the service industry than the manufacturing industry, it is important to be able to understand the quality of the services provides. However, due to the nature and intangibility of services, they are much more difficult to evaluate by consumers than goods. Additionally, the perceptions of service quality vary by the users expected and received services (Parasurman et al., 1985). Within the realm of fee fishing, the service quality is related to the level of expectations an angler has of their catch. Service quality is measured by a variety of indicators of quality that are measured and calculated through survey responses with the individual anglers. Some methods of measuring the service quality in the recreation fishing involve subjective responses to catch rates and quality of the fish caught, and others relate to calculated values of fishing success in terms of CPUE. This study chose to examine overall satisfaction with the quality of the experience, not the full models detailed within as the normative theory will be applied to the program evaluations.

In angling, the consumptive behavior seems to be the catching and keeping of the target species of the desired fish. However, in many instances, the consumption seems to be more 
abstract when the motivations for angling of the participant are not for consumption of the fish but for enjoyment of a premium angling experience. Holbrook (2000) noted that much of consumer behavior is related to the motivations of consumption. Therefore, individuals choose the goods and services they purchase based on emotions and motivations that may be unrelated to the utility of the consumption. Adapting Pine and Gilmore's (1999) definition of the "wearing experience" from that of a consumptive behavior where choices are made to purchase more expensive clothes when inexpensive alternatives exist due to the intrinsic value of those clothes is paralleled with the recreational fishing experience. While any stream stocked with fish presents the opportunity for an angler to catch fish, the additional payment of money to fish increases the users' satisfaction with the service due to the exclusivity or other factors obtained through the purchase. Also noted about these purchasing trends is that individuals choose more expensive options to items such as vehicles because it too lends itself to the exclusivity of the consumptive experience and not necessarily any differences in utility of the products (Holbrook, 2000).

Ellis and Rossman (2008) discuss the service of a plumber and how they are viewed, not only on their ability to fix a leaky pipe but also on different performance attributes. The benefits of the repair can be obtained from a variety of plumbers, but the service quality in reference to their reliability, empathy, assurance, cleanliness, and responsiveness are the additional factors that influence service quality (Cronin \& Taylor, 1994; Parasuraman, Zeithaml, \& Berry, 1988; Parasuraman, Berry, \& Zeithaml, 1991). Adapted to the angling experience, the comparison of public and private program formats involves more than just the ability to provide satisfactory catch rates. In the majority of the publicly stocked streams, the plumber, a roll fulfilled by the DNR or other stocking agency is quite passive. There is little, if any interaction between the 
anglers and those stocking the fish, and it is as if the plumber repairing the pipe completes the repair without any interaction with the homeowner, has no accountability for the repair, and while the service is offered, it may not be the service expected by the homeowner. Some may find this option acceptable due to the low cost of this option, but others may not. The private fishing venue has much more control over their role as the plumber. First of all, they are competing against other individuals that offer the service at higher and lower price points. Being that the service being provided to the consumer is identical, there must be a higher standard of the service quality offered. These service providers interact with the consumer in a way to manage the needs of the individual to provide the service quality expected with an increase in payment. These "plumbers" should be more adaptable and accommodating to the needs of their clients in a way that provides them with a satisfactory experience.

Individuals paying to access a stream for the benefits of the experience are similar to members of gyms and fitness centers. While the opportunities exist for both angling and fitness in publicly provided areas, their choice is made to pay for opportunities and a premium experience. While the fitness participants experience the benefits of overall health through the participation and membership to their respective gyms, anglers receive the benefits of decreased crowding and higher catch rates as fee fishing areas that manage the number of fish and anglers at the stream particularly as their motivations to receive those benefits increase due to deprivation caused by the overuse of the public resources (Butler \& Borgeson, 1965; Ellis \& Rossman, 2008; Finn \& Loomis, 2001). These service providers are also expected to maintain their operations under standards of quality so that user expectations are met at a level that continually drives their return for that service instead of choosing to go elsewhere due to unsatisfactory conditions (Ellis \& Rossman, 2008). 


\section{Fishing Motivations}

Motivations for travel tourism fall into push or pull factors. (Dann, 1977). This push-pull framework provides a method to understand travel behaviors and motivations (Dann, 1977; Klenosky, 2002). The push factors are what a tourist is subjected to that predispose him or her to the idea of travel, while pull factors are conditions such as weather that encourage a visitor to choose a certain area over another. The push motivations are tied to emotional and internal factors while the pull motivations are external factors that involve the situation or cognitive aspects (Yoon \& Uysal, 2005).

In the realm of fee fishing, these push and pull factors can help explain fishing participation and selection of fishing venue (Klenosky, 2002). While push factors explain why and when travel takes place and the pull factors explain what recreation opportunities are desired. Dann (1981) holds the perspective that these push and pull factors are distinct concepts. However, Klenosky (2002) feels that there is a relationship between the push and pull factors in tourism decision making.

Motivations to travel to a fishery for the experience can vary. Navratil, Martinsc, Picha, and Navr (2011) examined the travel and fishing motivations of Czech anglers. Their findings showed that both trout fishing destinations and large reservoir systems attracted individuals from greater distances than other types of fisheries. (This can be examined in this study as distance traveled for each fishing venue ranging on a spectrum of access) In their study, the style of fishing was a pull factor, as the distance traveled increased for certain styles. Anglers engage in the activity to attain trophy trout experiences. The desire for those experiences pull on the consumer to travel to these destinations. In this study, it is expected that anglers will travel the greatest distance for the most restricted fishing opportunities (i.e., fishing tournament on private 
land. Conversely, in the instance of open, unrestricted access, the pull may have an effect limited to the region or local area.

\section{Perceived Crowding}

Crowding is an important carrying capacity issue that managers of both public and private lands must be able to manage. s previously stated, for fee fishing and catch rates, simply increasing the number of fish in a stream is not a method that will increase catch rates for anglers. What needs to be done by management is to control the numbers of individuals fishing on the stream to a level that is reasonable (Butler \& Borgeson, 1965). Managers therefore must reduce crowding in these fishing venues for two different reasons, both for the maintenance of elevated catch rates for the "premium experience" as well as to reduce conflicts, both direct and indirect, between users.

Manning (2003) defined perceived crowding as it is relative to use levels, but also can be impacted by types of visitors, behaviors, and location of the encounters. In the realm of fee fishing, the perceived use levels for the stream can vary in several ways. In the peak season, particularly around stocking events where new fish have been added to the stream for anglers to catch, the number of individuals perceived to be crowding may be significantly higher than other times of the year. The angler's acceptability of increased number of other anglers may be influenced by the increased number of fish stocked in the stream. Other variables, such as the program format may also have an impact on user views of the levels of crowding, particularly in these private fishing destinations that offer the "premium experience" and the acceptability of the number of other anglers on the stream may be significantly less than that of the user of public land. 


\section{CHAPTER 3 \\ METHODOLOGY}

\section{Introduction}

Face to face surveys were the primary instrument used to collect data in this study. This four-page survey was adapted from the previous creel surveys to understand catch-related factors, fishing motivations, and economic impacts of visitors at Pipestem State Park from 20082010 and Harman's North Fork Cottages in 2011. Site managers added other questions to the survey forms to obtain additional visitor information specific to their site. This research is a replication and extension of their previous work as it relates to fishing in West Virginia.

Controlling access to streams is another approach to dealing with this carrying capacity issue. Both public and private resource managers have approached this problem in different ways and with various limits of control. For example, Pipestem State Park managers provided anglers with access to the Bluestone River with few controls via an arial tramway prior to 2009 . In recent years, the park has controlled access by stocking trout at the beginning of the shoulder season (November-April) when the tram is closed, thus limiting access to the river via a strenuous 4 mile hike on steep terrain. At Harman's North Fork Cottages, access is controlled on private land. Only guests that stay in the luxury log cabins are given easy and nearby access to a small segment of the North Fork of the South Branch of the Potomac River

\section{Study Locations and Data Collection}

Data were collected at two sampling locations in West Virginia (Pipestem Resort State Park and Harman's North Fork Cottages). The venues offered at the study sites offer a range of trout fishing opportunities including open access-unguided anglers, open access-guided anglers, restricted access-unguided anglers, and restricted access-tournament anglers.

Pipestem Resort State Park-This park is located 14 miles north of Princeton and 12 
miles south of Hinton in southeastern West Virginia. The Bluestone River is a National Scenic River and a small segment is located in the park. The river is either accessible via a tram or a steep 4 mile hike or horseback ride from the state park to the river valley on one side of the river, depicted in Figure 6. Private property and the state park lodge flanks the other side of the river making it difficult to access the river when the tram closes during the late fall and early spring fishing seasons. Guided fishing packages, as shown in Figure 7, including horseback riding, are offered during the offseason. As part of this study, a total of 4,043 small rainbow trout (1-2 pounds) and 240 large rainbow trout (over 3 pounds) were stocked during the 6 seasons starting in October 2007. (No data were collected during the first season). That is, about 700 to 750 rainbow trout were stocked every season.

Guided and non-guided Pipestem anglers were contacted and asked to participate in the study at the end of their fishing trip. Non-guided anglers were contacted on all weekends and 2 randomly selected weekdays in May and June (2008). A total of 49 non-guided anglers were contacted (response rate $=88 \%$ ). An effort was made to contact every guided angler that participated in the fishing package during November (2008), April and May (2009), October (2009), and April (2010). A total of 42 guided anglers were contacted (response rate=100\%). Harman's North Fork Cottages-- Harman's North Fork Cottages is a trophy trout fishing destination located on the North Fork of the South Branch of the Potomac River in Cabins, West Virginia. The managers of Harman's maintain five miles of private access and privately stocked trout fishing waters along their property. In addition to providing catch-and-release fishing opportunities to their guests, they manage twenty luxury log cabins for their guests to rent during their stay. All who wish to fish on the property must be guests in one of the cabins, and thus this limits the total numbers of anglers fishing the stream and prevents walk-in anglers during busy 
parts of the fishing season. Harman's has been stocking their portion of the stream with rainbow trout for several decades, and they have established themselves as a favorite fishing destination for many angers in West Virginia, Virginia, Ohio, Maryland and other surrounding areas. Figure 8 shows a lone angler fishing the private waters of Harman's North Fork Cottages, and Figure 9 depicts the tournament atmosphere from the invitation only tournament hosted by the resort comprising the Restricted Access - Tournament Anglers.

Researchers attempted to contact all Harman's North Fork Cottages anglers during the sampling days. All adults (age 16 or older) contacted were asked to participate in the study during room check-out. Interviews took place on 7 weekends in March, April and May (2011). A total of 34 anglers participated in the study (response rate $=76 \%$ ), and 18 tournament anglers were contacted (response rate 100\%). Additionally, 18 non-anglers were contacted and surveyed as they exited the site. 


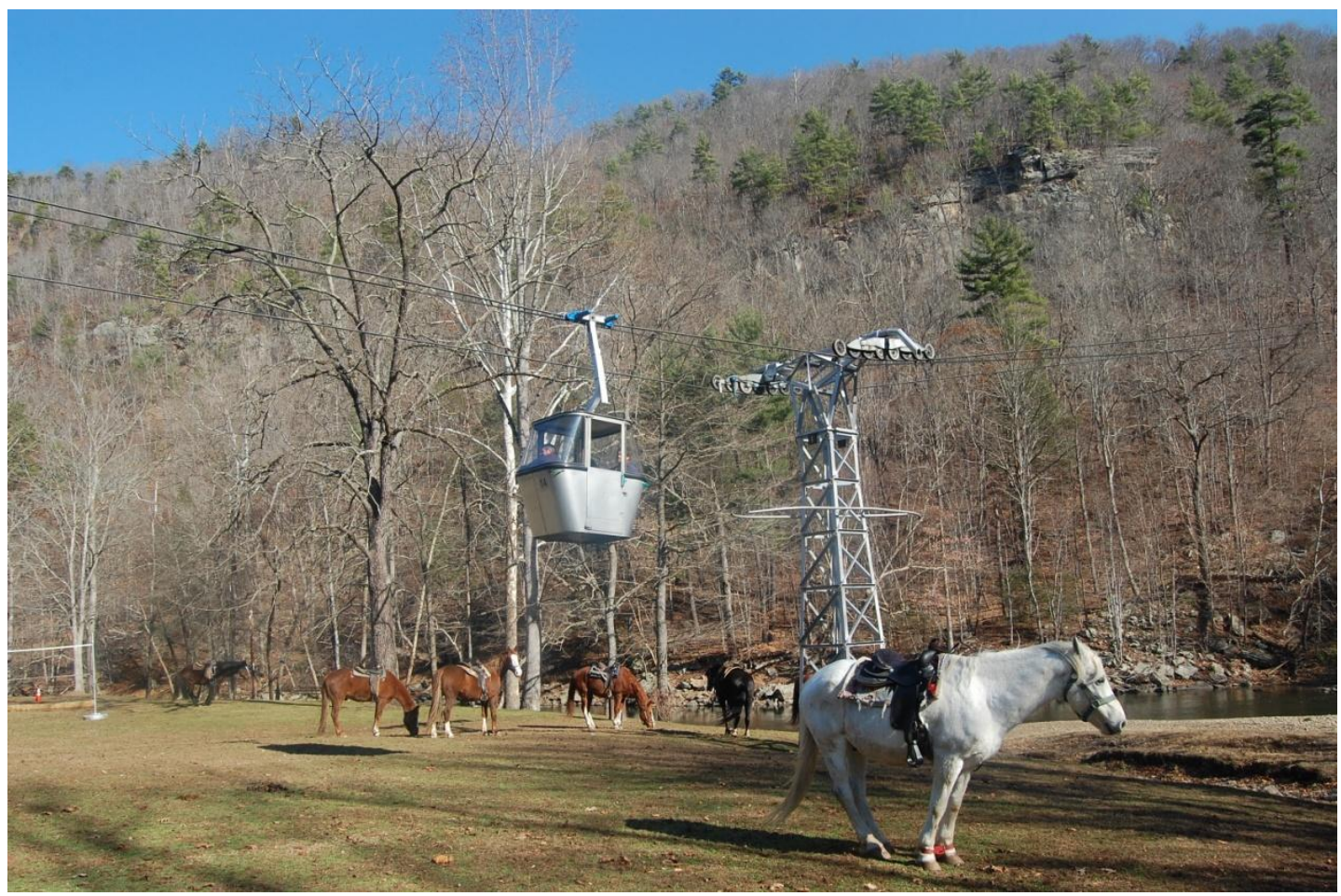

Figure 6. Horses and Tram - Access to Bluestone River Gorge in Pipestem State Park and Resort

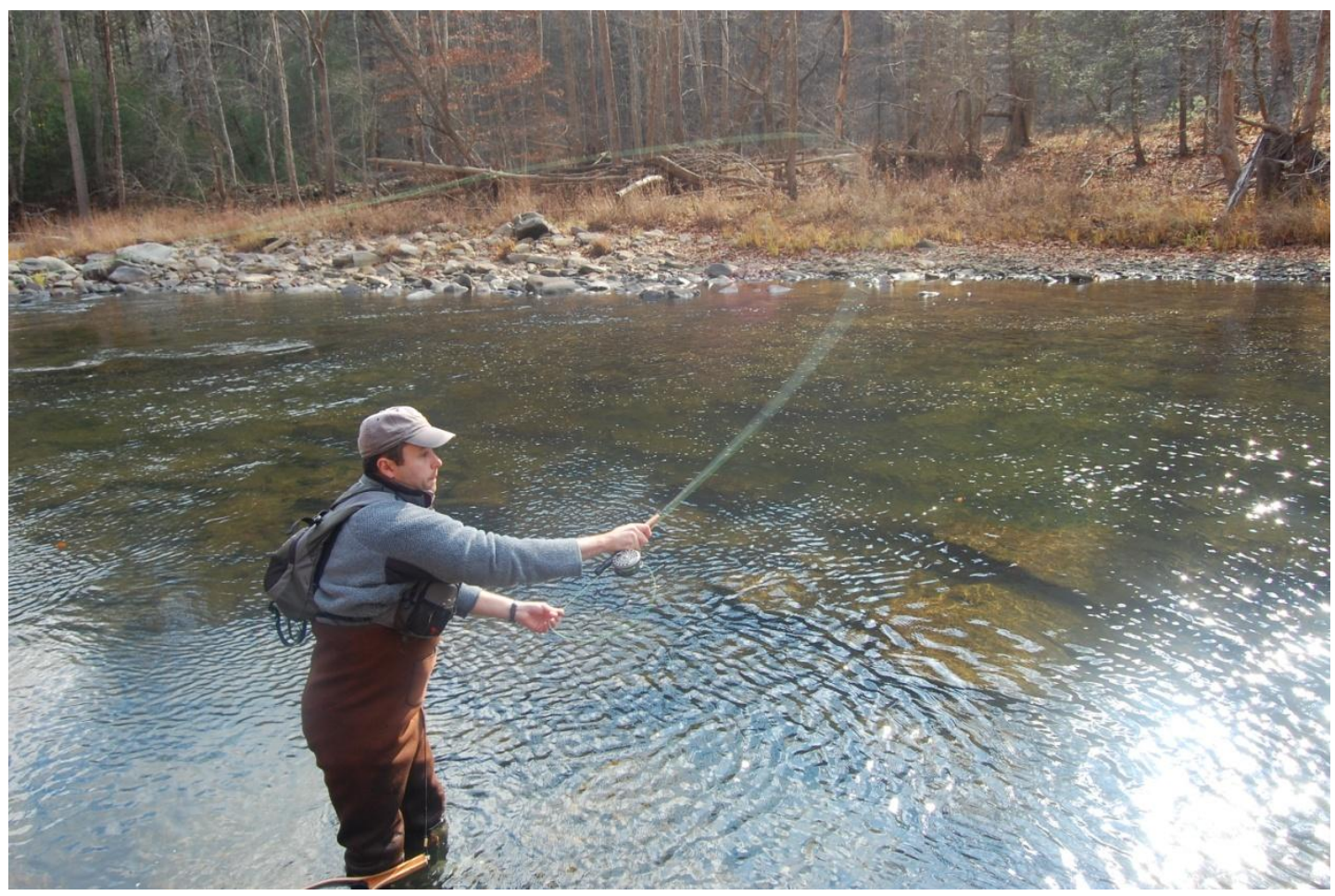

Figure 7. A Guide Instructing Guests at Pipestem State Park and Resort 


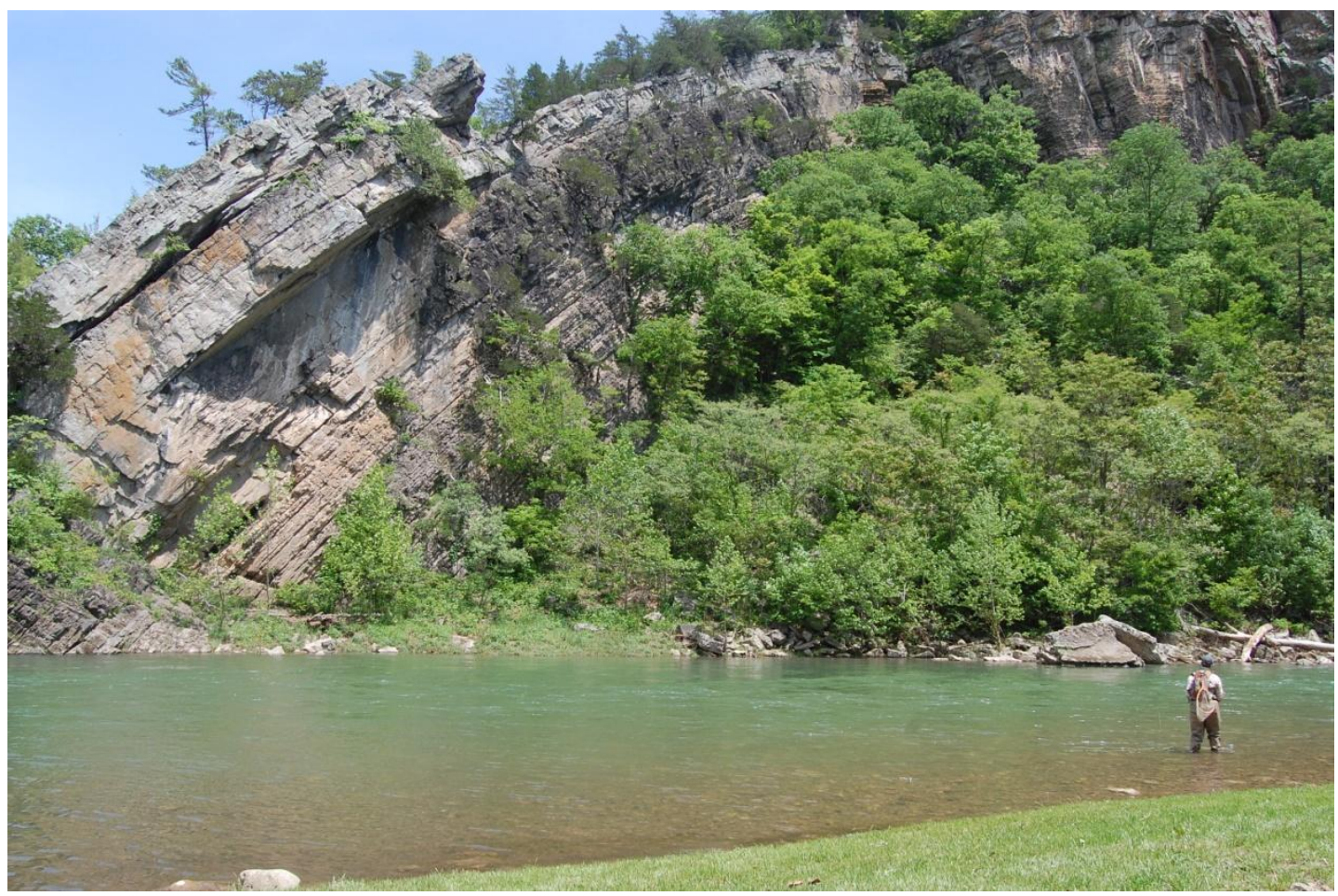

Figure 8. An Angler Fishes at Harman's North Fork Cottages

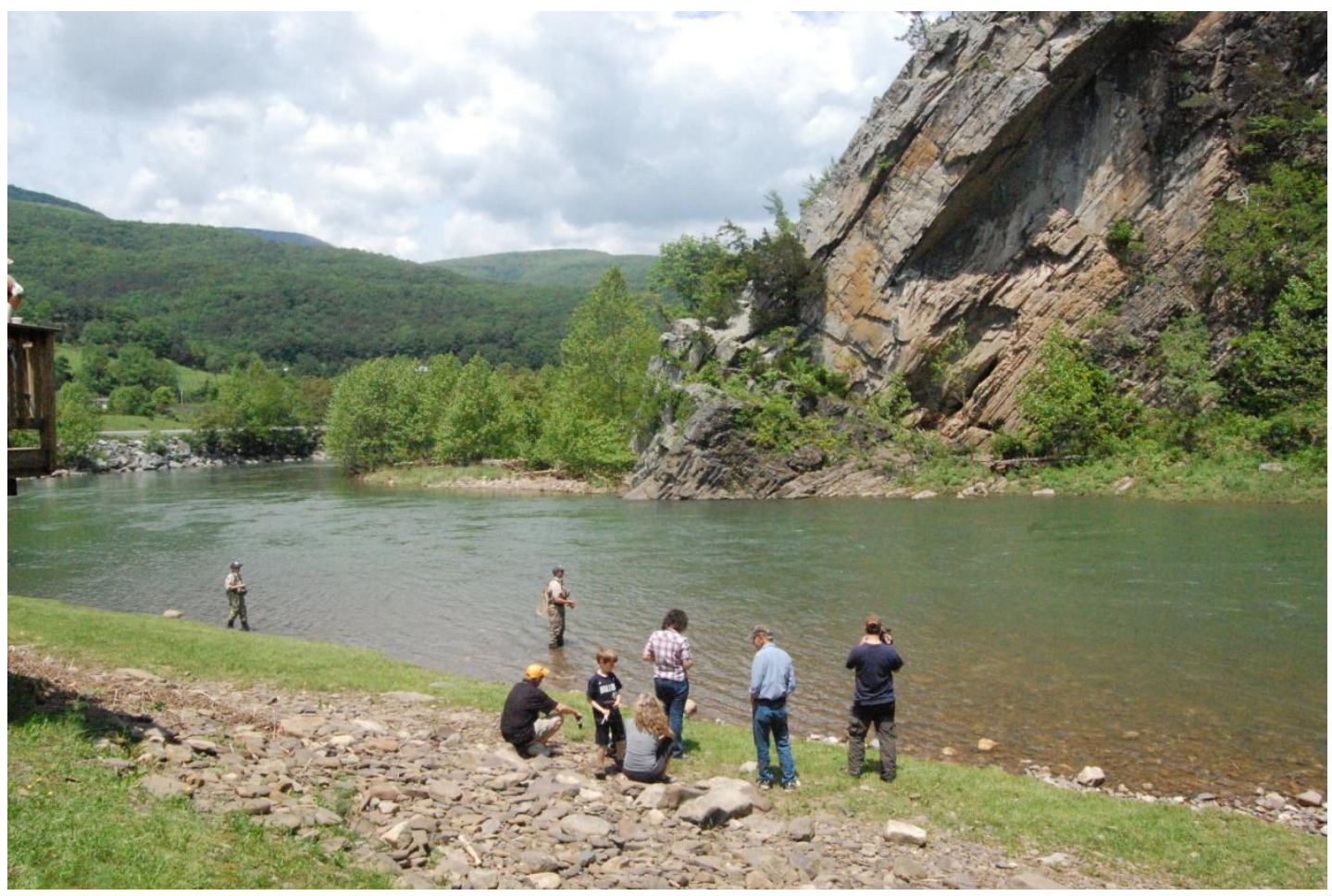

Figure 9. Tournament Spectators at Harman's North Fork Cottages 


\section{Instrumentation}

An on-site interview survey (creel survey), consisting of 35 questions, was developed to measure angler and trip characteristics, time spent fishing, number of fish caught, species of fish caught, and number of rainbow trout that were greater than 4 pounds. The acceptability of the catch-related indicators were measure on a 7 -point scale $(-3=$ very unacceptable to $+3=$ very acceptable). The specific catch-related indicators evaluated include 'total number of fish caught per hour', 'proportion of catch consisting of rainbow trout that are greater than 4 pounds', 'size of the largest trout caught', 'variety of species caught', and 'color and health of rainbow trout caught'. Respondents were asked "How eventful would you consider your fishing experience on this river during this trip?" Respondents were also asked "How do you rate the overall quality of your fishing experiences on this river during this trip?" Responses to this question were recorded on a 7-point scale ( $1=$ poor to $7=$ excellent). (Note: productivity is a multiplication of eventfulness and quality measurements). To pretest the instrument, a total of 19 anglers over age 18 were contacted at Long Branch Lake (located in Pipestem Resort State Park) during two days in April, 2007--shortly after the DNR stocked the lake. Based on preliminary findings, the number of catch-related indicators was expanded to five items in the final creel survey. Interviewers from West Virginia University and Concord University were trained prior to data collection.

Respondents were asked to rate catch related factors on a scale that ranged from ' 3 ' Very Unacceptable to " +3 " Very Acceptable for those rounds of question. The final scale asked respondents to rate their overall trip experience, from fishing to accommodations as well as other recreational activities they participated in while on their trip. The scale ranged from ' 1 ' Poor to '7' Excellent. 
Additional questions in the survey collected demographic information from the respondents. Age, race and ethnicity, marital status, group size, household income and traveling distance were all included in the series of questions. Additionally, the survey instrument included questions as about respondent's financial investment in fishing supplies as well as the number of fishing shows and tournaments that were watched on television in the past twelve months.

For the guided anglers on public land, an online survey was available for those individuals to complete after they had left the study site. This survey was a condensed form of the on-site surveys that were administered. It included the questions related to catch related factors and indicators of quality for the angling experience - the focus of this study. Tournament anglers are shown completing the survey post competition in Figure 10.

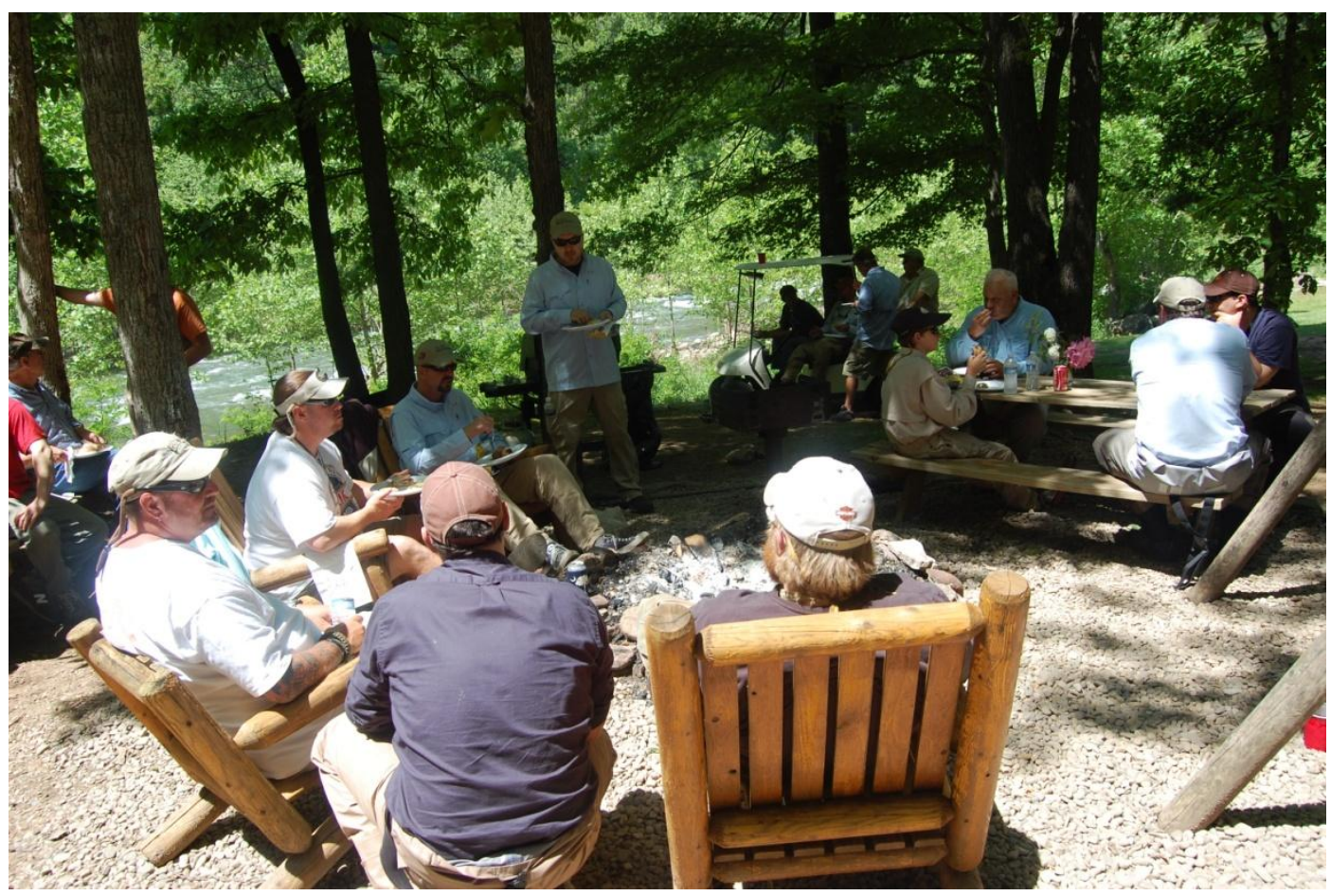

Figure 10. Tournament Anglers Completing Survey at Harman's North Fork Cottages 


\section{$\underline{\text { Treatment of Data }}$}

All usable responses from the onsite and online surveys were collected, entered, and analyzed within IBM SPSS Version 19 for Windows. Non-angler surveys were also collected from the Harman's North Fork Cottages site but only demographic information was included in the analysis and reported. The Scheffé post hoc method was used for the comparisons drawn with the One-way Analyses of Variance due to the conservative nature of the test and ability to handle sample sizes of different number.

\section{Addressing the Research Questions}

$\mathrm{R}_{1}$ : What are the visitor characteristics of the four different fishing venues?

Descriptive Statistics

$\mathrm{R}_{2}$ : How do catch-related factors of quality differ by fishing venues?

One-way Analysis of Variance

$\mathrm{R}_{3}$ : What are the ranges of acceptable catch-rates (including preferred and minimum acceptable condition) for the fishing venues?

One-way Analysis of Variance

$\mathrm{R}_{4}$ : How does overall quality of the fishing experience and willingness to pay differ among the fishing venues?

One-way Analysis of Variance

$\mathrm{R}_{5}$ : What relationships exist between access, age, gender, site visitation, and annual angling expenses as they relate to catch rates?

Linear Regression Model 


\section{CHAPTER 4}

RESULTS

\section{$\underline{\text { Introduction }}$}

The results are presented in the same order as the research questions listed in Chapter 3. Each section restates the research question as outlined in Chapter 2. Each section includes figures and tables that report results from statistical analysis, and concludes with discussion of the statistical tests.

\section{Participant Profile}

On-site interviews and web-based surveys were conducted. One hundred forty-five useable surveys were collected (response rate $=89.0 \%$ ) (Table 1). Additionally, nine usable webbased surveys were collected totaling one hundred fifty-four total usable surveys (Table 2). Of the total number of surveys collected, multiple user groups were identified from the two study sites. Of the 145 completed onsite surveys: 33 (21.4\%) were conducted with package anglers from Pipestem Resort State Park, 43 (27.9\%) were conducted with drop-in anglers from Pipestem Resort State Park, 33 (21.4\%) were conducted with anglers at Harman's North Fork Cottages, $18(11.7 \%)$ were conducted with non-anglers at Harman's North Fork Cottages, and 18 (11.7\%) were conducted with tournament anglers at Harman's North Fork Cottages during an annual Professional-Amateur fly fishing tournament. The remaining 9 (5.8\%) of the surveys were web-based and collected from package anglers from Pipestem Resort State Park (Table 3).

TABLE 1. On-site Interview Response Rate

\begin{tabular}{ccc}
\hline & & \\
Anglers Contacted & Complete On-Site Interviews & Response Rate \\
\hline 163 & 145 & $89.0 \%$ \\
\hline
\end{tabular}

TABLE 2. Total Sample Size

Complete On-Site Interviews

Web Survey Responses

Total Surveys Collected

145

9

154


TABLE 3. Survey Instruments Collected by Fishing Venue

\begin{tabular}{ccccc} 
& $\begin{array}{c}\text { On-Site Interviews } \\
n\end{array}$ & Percent of Total & Web Survey & $\begin{array}{c}\text { Percent of } \\
\text { Total }\end{array}$ \\
\hline $\begin{array}{l}\text { Open Access: } \\
\text { Guided Angler }\end{array}$ & 33 & 21.4 & 9 & 5.8 \\
$\begin{array}{c}\text { Open Access: } \\
\text { Unguided Angler }\end{array}$ & 43 & 27.9 & - & - \\
$\begin{array}{c}\text { Restricted Access: } \\
\text { Unguided Angler }\end{array}$ & 33 & 21.4 & - & - \\
$\begin{array}{c}\text { Restricted Access: } \\
\text { Non-Angler }\end{array}$ & 18 & 11.7 & - & - \\
$\begin{array}{c}\text { Restricted Access: } \\
\text { Invitation Angler }\end{array}$ & 18 & 11.7 & - & - \\
\hline
\end{tabular}

\section{Visitor Characteristics -All Groups}

The socioeconomic data gathered included: gender and marital status (Table 4), annual income and race (Table 5), age and distance traveled (Table 6), as well as site visitation (Table 7). The sample consisted of more men than women: $126(82.9 \%)$ males and $26(17.1 \%)$ females. Most respondents $(\mathrm{n}=67,43.8 \%)$ reported a marital status of Married, no children, followed by Married, with children $(\mathrm{n}=39,25.5 \%) ;$ Single, no children $(\mathrm{n}=27,17.6 \%)$; and lastly one response each for Domestic Partnership $(\mathrm{n}=1,0.7 \%)$ and for Other $(\mathrm{n}=1,0.7 \%)$. On reported annual income, one third of the respondents listed their household income at Over $\$ 100,000(\mathrm{n}=$ $47,33.3 \%)$; followed by $\$ 60,000$ to $\$ 79,000$ ( $\mathrm{n}=32,22.7 \%), \$ 40,000$ to $\$ 59,000$ ( $\mathrm{n}=24,17.0 \%)$, $\$ 20,000$ to $\$ 39,000(\mathrm{n}=17,12.1 \%), \$ 80,000$ to $\$ 99,000(\mathrm{n}=13,9.2 \%)$, and finally, Less than $\$ 20,000(n=8,5.7 \%)$. In terms of race or ethnicity, an overwhelming number of respondents are Caucasian $(\mathrm{n}=148,97.4 \%)$; followed by Other $(\mathrm{n}=2,1.3 \%)$; Native American-Native Alaskan $(\mathrm{n}=1, .65 \%)$ and Asian-American $(\mathrm{n}=1, .65 \%)$. No responses were collected for: Hispanic, African-American, or Pacific Islander. Response to age, the average age $(n=150)$ of the participant was 45.55 , with a range of $16-79$, and a median of 45 years. Respondents $(n=153)$ 
traveled on average of 219.22 miles to their destination, with a range of 2-2,100 miles, and a median of 346.08 miles. Of the respondents $(n=153), 98(64.1 \%)$ were repeat visitors and 55 (35.9\%) were first time visitors of the study site.

TABLE 4. Visitor Characteristics (Gender, Marital Status)

\begin{tabular}{lcc}
\hline & Frequency & Percent of Total \\
\hline$\underline{\text { Gender }(n=152)}$ & 126 & 82.9 \\
Male & 26 & 17.1 \\
Female & & \\
Marital Status $(n=153)$ & 27 & 17.6 \\
Single, no children & 18 & 11.8 \\
Single, with children & 67 & 43.8 \\
Married, no children & 39 & 25.5 \\
Married, with children & 1 & 0.7 \\
Domestic Partnership & 1 & 0.7 \\
Other &
\end{tabular}

Note: Total number of respondents may vary due to missing data.

TABLE 5. Visitor Characteristics (Annual Income, Race)

\begin{tabular}{lcc}
\hline \multicolumn{2}{l}{ Income US Dollars $(n=141)$} & Prequency \\
\hline Less than $\$ 20,000$ & 8 & 5.7 \\
$\$ 20,000$ to $\$ 39,000$ & 17 & 12.1 \\
$\$ 40,000.00$ to $\$ 59,000$ & 24 & 17.0 \\
$\$ 60,000$ to $\$ 79,000$ & 32 & 22.7 \\
$\$ 80,000$ to $\$ 99,000$ & 13 & 9.2 \\
Over $\$ 100,000$ & 47 & 33.3 \\
& & \\
Race $(n=152)$ & 148 & 97.4 \\
Caucasian & 0 & 0.0 \\
Hispanic & 0 & 0.0 \\
African American & 1 & .65 \\
Native American - Native & 0 & 0.0 \\
Alaskan & 1 & .65 \\
Pacific Islander & 2 & 1.3 \\
Asian-American & & \\
Other & & \\
\hline
\end{tabular}

Note: Total number of respondents may vary due to missing data. 
TABLE 6. Visitor Characteristics (Age, Distance Traveled)

\begin{tabular}{lcccc} 
& $n$ & Range & Mean & Median \\
\hline Age & 150 & $16-79$ & 45.55 & 45 \\
Distance Traveled & 153 & $2-2,100$ & 219.22 & 346.08 \\
\hline
\end{tabular}

Note: Total number of respondents may vary due to missing data.

TABLE 7. Angler Use History

Frequency Percent of Total

$\underline{\text { Visitation }(n=153)}$

Repeat Visitor

First Time Visitor
98

55
64.1

35.9

Note: Total number of respondents may vary due to missing data.

\section{Visitor Characteristics -- Open Access Anglers (Guided and Unguided)}

The socioeconomic data gathered included: gender and marital status (Table 8), annual income and race (Table 9), age and distance traveled (Table 10), as well as site visitation (Table 11). The sample was predominately male: $72(85.7 \%)$ males and $12(14.3 \%)$ females. Over twothirds $(\mathrm{n}=57,67.9 \%)$ reported a marital status of Married, no children, followed by Single, with children $(\mathrm{n}=12,14.3 \%) ;$ Single, no children $(\mathrm{n}=11,13.1 \%) ;$ Married, with children $(\mathrm{n}=3,3.6 \%)$ and lastly one response for Other $(\mathrm{n}=1,1.2 \%)$. No responses were collected for Domestic Partnership. Over $\$ 100,000(\mathrm{n}=24,28.8 \%)$ annual was reported by respondents; followed by $\$ 60,000$ to $\$ 79,000(\mathrm{n}=19,22.9 \%), \$ 40,000$ to $\$ 59,000(\mathrm{n}=15,18.1 \%), \$ 20,000$ to $\$ 39,000$ $(n=11,13.3 \%), \$ 80,000$ to $\$ 99,000(n=8,9.6 \%)$, and lastly Less than $\$ 20,000(n=6,7.2 \%)$. An overwhelming percent of respondents are Caucasian $(n=81,96.4 \%)$; followed by Other $(n=2$, 2.4\%); and Native American-Native Alaskan $(\mathrm{n}=1,1.2 \%)$. No responses were collected for: Hispanic, African-American, Asian-American or Pacific Islander. The average age $(\mathrm{n}=83)$ of the participant was 47.63 , with a range of $16-79$ years, and a median of 49 years. Respondents $(n=84)$ traveled on average of 144.31 miles to the study site where they were contacted, with a range of 2-2,000 miles, and a median of 120.0 miles. Of all the respondents $(n=84), 57(67.9 \%)$ 
were repeat visitors and $27(32.1 \%)$ were first time visitors to their site.

TABLE 8. Visitor Characteristics (Gender, Marital Status)--Open Access

\begin{tabular}{lcc}
\hline & Frequency & Percent of Total \\
\hline $\begin{array}{l}\text { Gender }(n=84) \\
\text { Male }\end{array}$ & 72 & 85.7 \\
Female & 12 & 14.3 \\
Marital Status $(n=84)$ & & \\
Single, no children & 11 & 13.1 \\
Single, with children & 12 & 14.3 \\
Married, no children & 57 & 67.9 \\
Married, with children & 3 & 3.6 \\
Domestic Partnership & 0 & 0 \\
Other & 1 & 1.2 \\
\hline
\end{tabular}

Note: Total number of respondents may vary due to missing data.

TABLE 9. Visitor Characteristics (Annual Income, Race)--Open Access

\begin{tabular}{lcc}
\hline & Frequency & Percent of Total \\
\hline Income $(n=83)$ & 6 & 7.2 \\
Less than $\$ 20,000$ & 11 & 13.3 \\
$\$ 20,000$ to $\$ 39,000$ & 15 & 18.1 \\
$\$ 40,000.00$ to $\$ 59,000$ & 19 & 22.9 \\
$\$ 60,000$ to $\$ 79,000$ & 8 & 9.6 \\
$\$ 80,000$ to $\$ 99,000$ & 24 & 28.9 \\
Over $\$ 100,000$ & & \\
& & \\
Race $(n=91)$ & 81 & 06.4 \\
Caucasian & 0 & 0 \\
Hispanic & 0 & 1.2 \\
African American & 1 & 0 \\
Native American - Native & 0 & 0 \\
Alaskan & 0 & 2.4 \\
Pacific Islander & 2 & \\
Asian-American & & \\
Other & & \\
\hline Note: Total number of respondents may vary & & \\
\hline
\end{tabular}

Note: Total number of respondents may vary due to missing data. 
TABLE 10. Visitor Characteristics (Age, Distance Traveled)--Open Access

\begin{tabular}{lcccc} 
& $n$ & Range & Mean & Median \\
\hline Age & 83 & $16-79$ & 47.64 & 49 \\
Distance Traveled & 84 & $2-2000$ & 144.31 & 120.00 \\
\hline
\end{tabular}

Note: Total number of respondents may vary due to missing data.

TABLE 11. Angler Use History--Open Access

Frequency

Percent of Total

Visitation $(n=153)$

Repeat Visitor

27

First Time Visitor

57

67.9

32.1

Note: Total number of respondents may vary due to missing data.

Visitor Characteristics--Restricted Access (Unguided, Non-Angler, and Invitation)

The socioeconomic data gathered included: gender and marital status (Table 12), annual income and race (Table 13), age and distance traveled (Table 14), as well as site visitation and fishing participation (Table 15). The sample consisted of more men than women: 54 (79.4\%) males and $14(20.6 \%)$ females. Over half of the respondents $(n=36,52.2 \%)$ reported a marital status of Married, with children, followed by Single, no children $(\mathrm{n}=16,23.2 \%)$; Married, no children $(\mathrm{n}=10,14.5 \%)$; Single, with children $(\mathrm{n}=6,8.7 \%)$ and lastly one response for Domestic Partnership ( $\mathrm{n}=1,1.4 \%)$ and no responses were collected for Other. On reported annual income, over one-third of the respondents listed their household income at Over $\$ 100,000(\mathrm{n}=23$, $39.7 \%)$; followed by $\$ 60,000$ to $\$ 79,000(\mathrm{n}=13,22.4 \%), \$ 40,000$ to $\$ 59,000$ ( $\mathrm{n}=9,15.5 \%)$, $\$ 20,000$ to $\$ 39,000(\mathrm{n}=6,10.3 \%), \$ 80,000$ to $\$ 99,000(\mathrm{n}=5,8.6 \%)$, and lastly Less than $\$ 20,000$ $(n=2,3.4 \%)$. An overwhelming percent of respondents are Caucasian $(n=61,98.4 \%)$; followed by Asian American (n=1, 1.6\%); and Native American-Native Alaskan $(\mathrm{n}=1,1.2 \%)$. No responses were collected for: Hispanic, African-American, Native American-Native Alaskan or Pacific Islander. Response to age, the average age $(n=67)$ of the participant was 41.99 years, 
with a range of 23-70 years, and a median of 42 . Respondents $(n=69)$ traveled on average of 310.42 miles to their site, with a range of 3-2,100 miles, and a median of 160.0 miles. Of the all the respondents $(n=69), 41(59.4 \%)$ were repeat visitors and $28(40.6 \%)$ were first time visitors of the study site where they were contacted. Also asked at Harman's North Fork Cottages was fishing show and tournament participation. Over one-third of respondents $(n=25,36.8 \%)$ reported watching 16 or more fishing shows or tournaments annually, followed by None $(\mathrm{n}=21$, 30.9\%), 6-10 fishing shows or tournaments annually and 11-15 fishing shows or tournaments annually both received eight responses (11.8\%), and lastly Less than 5 fishing shows or tournaments annually received six $(8.8 \%)$ responses.

TABLE 12. Visitor Characteristics (Gender, Marital Status)--Restricted Access

Frequency Percent of Total

$\underline{\text { Gender }(\mathrm{n}=68)}$

Male 54

79.4

Female

Marital Status $(n=69)$

Single, no children

Single, with children

Married, no children

Married, with children

36

52.2

Domestic Partnership

Other

0

Note: Total number of respondents may vary due to missing data. 
TABLE 13. Visitor Characteristics (Annual Income, Race)--Restricted Access

\begin{tabular}{lcc}
\hline & Frequency & Percent of Total \\
\hline$\underline{\text { Income }(n=83)}$ & 2 & 3.4 \\
Less than $\$ 20,000$ & 6 & 10.3 \\
$\$ 20,000$ to $\$ 39,000$ & 9 & 15.5 \\
$\$ 40,000.00$ to $\$ 59,000$ & 13 & 22.4 \\
$\$ 60,000$ to $\$ 79,000$ & 5 & 8.6 \\
$\$ 80,000$ to $\$ 99,000$ & 23 & 39.7 \\
Over $\$ 100,000$ & & \\
& & \\
Race $(n=62)$ & 61 & 08.4 \\
Caucasian & 0 & 0 \\
Hispanic & 0 & 0 \\
African American & 0 & 0 \\
Native American - Native & 0 & 1.6 \\
$\quad$ Alaskan & 0 & 0 \\
Pacific Islander & 1 & 0 \\
Asian-American & 0 & \\
Other &
\end{tabular}

Note: Total number of respondents may vary due to missing data.

TABLE 14. One Measure of Angler Use History and Activity Specialization--Restricted Access

\begin{tabular}{|c|c|c|}
\hline & Frequency & Percent of Total \\
\hline \multicolumn{3}{|l|}{ Visitation $(n=69)$} \\
\hline Repeat Visitor & 41 & 59.4 \\
\hline First Time Visitor & 28 & 40.6 \\
\hline \multicolumn{3}{|c|}{ Fishing Tournaments and Shows Watched } \\
\hline None & 21 & 30.9 \\
\hline 5 or less shows/tournaments & 6 & 8.8 \\
\hline 6 to 10 shows/tournaments & 8 & 11.8 \\
\hline 11 to 15 shows/tournaments & 8 & 11.8 \\
\hline 16 or more show/tournaments & 25 & 36.8 \\
\hline
\end{tabular}

Note: Total number of respondents may vary due to missing data.

TABLE 15. Visitor Characteristics (Age, Distance Traveled) Restricted Access

\begin{tabular}{lcccc} 
& $n$ & Range & Mean & Median \\
\hline Age & 67 & $23-70$ & 41.99 & 42.00 \\
Distance Traveled & 69 & $3-2,100$ & 310.42 & 160.00 \\
\hline
\end{tabular}

Note: Total number of respondents may vary due to missing data. 


\section{Catch Related Factors of Quality Fishing Experiences}

Anglers were asked a battery of five catch related factors to assess their fishing experience. Table 16 reflects the combined angler responses from both Pipestem Resort State Park and Harman's North Fork Cottages. Results for the five factors are as followed, listed in de order: Factor \#1 - Total Number of Fish Caught Per Hour $(\mathrm{n}=130, M=1.09$, median = 2.00), Factor \#2 - Proportion of Catch Consisting of Rainbow Trout Greater than 20" $(\mathrm{n}=117, M=.45$, median $=.00)$, Factor \#3 Size of Largest Trout Caught $(\mathrm{n}=110, M=1.58$, median $=2.00)$, Factor $\# 4$ - Variety of Species Caught $(\mathrm{n}=116, M=1.09$, median $=2.00)$, and Factor $\# 5-$ Color and Heath of Rainbow Trout Caught $(\mathrm{n}=109, M=2.14$, median $=3.00)$.

TABLE 16. Catch Related Factors of Quality of Fishing Experience

\begin{tabular}{lcc}
\hline & Mean & Median \\
\hline $\begin{array}{l}\text { Total Number of Fish Caught Per Hour } \\
(n=130)\end{array}$ & 1.09 & 2.00 \\
Proportion of catch consisting of rainbow trout & .45 & .00 \\
that are greater than 20" $(n=117)$ & 1.58 & 2.00 \\
Size of largest trout caught $(n=110)$ & 1.09 & 2.00 \\
Variety of species caught $(n=116)$ & 2.14 & 3.00 \\
Color and health of rainbow trout caught & $(n=109)$ & \\
\hline
\end{tabular}

Note: Total Number of respondents may vary due to missing data.

In an effort to assess the efforts of stocking fish at Pipestem Resort State Park, Table 17 reflects all responses collected from both package and open access anglers. Results for the five factors are as followed, listed in order: Factor \#1 - Total Number of Fish Caught Per Hour (n=79, $M=1.19$, median $=2.00$ ), Factor \#2 - Proportion of Catch Consisting of Rainbow Trout Greater than 20" $(\mathrm{n}=76, M=.43$, median $=.00)$, Factor \#3 Size of Largest Trout Caught $(\mathrm{n}=69, M=$ 1.62 , median $=2.00)$, Factor $\# 4-$ Variety of Species Caught $(\mathrm{n}=74, M=.92$, median $=1.00)$, and Factor $\# 5$ - Color and Heath of Rainbow Trout Caught $(\mathrm{n}=68, M=2.15$, median $=3.00)$. 
TABLE 17. Catch Related Factors-Open Access

\begin{tabular}{lcc} 
& Mean & Median \\
\hline Total Number of Fish Caught Per Hour $(n=79)$ & 1.19 & 2.00 \\
Proportion of catch consisting of rainbow trout & .43 & 0.00 \\
that are greater than 20" $(n=76)$ & 1.62 & 2.00 \\
Size of largest trout caught $(n=69)$ & .92 & 1.00 \\
Variety of species caught $(n=74)$ & 2.15 & 3.00 \\
Color and health of rainbow trout caught & $(n=68)$ &
\end{tabular}

Note: The total number of respondents may vary due to missing data.

In Table 18, only the catch related factors from open access anglers at Pipestem Resort State Park are reported. Results for the five factors are as followed, listed in order: Factor \#1 Total Number of Fish Caught Per Hour $(\mathrm{n}=43, M=1.58$, median = 2.00), Factor \#2 - Proportion of Catch Consisting of Rainbow Trout Greater than 20” $(\mathrm{n}=41, M=.37$, median $=.00)$, Factor \#3 Size of Largest Trout Caught $(\mathrm{n}=35, M=1.69$, median = .00), Factor \#4 - Variety of Species Caught $(\mathrm{n}=40, M=1.48$, median $=2.00)$, and Factor \#5 - Color and Heath of Rainbow Trout Caught $(\mathrm{n}=37, M=2.22$, median $=3.00)$.

TABLE 18. Catch Related Factors--Open Access Unguided Anglers

\begin{tabular}{lcc} 
& & Mean \\
\hline Total Number of Fish Caught Per Hour $(n=43)$ & 1.58 & 2.00 \\
Proportion of catch consisting of rainbow trout & .37 & .00 \\
that are greater than $20 "(n=41)$ & 1.69 & .00 \\
Size of largest trout caught $(n=35)$ & 1.48 & 2.00 \\
Variety of species caught $(n=40)$ & 2.22 & 3.00 \\
Color and health of rainbow trout caught & $(n=37)$ &
\end{tabular}

Note: The total number of respondents may vary due to missing data.

In Table 19, only the catch related factors from guided, package anglers at Resort State Park are reported. Results for the five factors are in order: Factor \#1 - Total Number of Fish Caught Per Hour $(\mathrm{n}=36, M=.72$, median = 2.00), Factor \#2 - Proportion of Catch Consisting of Rainbow Trout Greater than 20" (n=35, M=.51, median = 1.00), Factor \#3 Size of Largest Trout 
Caught $(\mathrm{n}=34, M=1.56$, median $=2.00)$, Factor $\# 4$ - Variety of Species Caught $(\mathrm{n}=34, M=.26$, median $=.50)$, and Factor $\# 5-$ Color and Heath of Rainbow Trout Caught $(\mathrm{n}=31, M=2.06$, median $=3.00)$.

TABLE 19. Catch Related Factors-- Open Access Guided Anglers

\begin{tabular}{lcc}
\hline & Mean & Median \\
\hline Total Number of Fish Caught Per Hour $(n=36)$ & .72 & 2.00 \\
Proportion of catch consisting of rainbow trout & .51 & 1.00 \\
that are greater than 20" $(n=35)$ & 1.56 & 2.00 \\
Size of largest trout caught $(n=34)$ & .26 & .50 \\
Variety of species caught $(n=34)$ & 2.06 & 3.00 \\
Color and health of rainbow trout caught & $(n=31)$ & \\
\hline
\end{tabular}

Note: The total number of respondents may vary due to missing data.

In Table 20, only the catch related factors from open access anglers at Harman's North Fork Cottages are reported. Results for the five factors are as followed, listed in order: Factor \#1

- Total Number of Fish Caught Per Hour $(\mathrm{n}=51, M=.94$, median = 1.00), Factor \#2 - Proportion of Catch Consisting of Rainbow Trout Greater than 20” $(\mathrm{n}=41, M=.49$, median $=.00)$, Factor \#3 Size of Largest Trout Caught $(\mathrm{n}=41, M=1.51$, median $=2.00)$, Factor \#4 - Variety of Species Caught $(\mathrm{n}=42, M=1.40$, median $=2.00)$, and Factor \#5 - Color and Heath of Rainbow Trout Caught $(\mathrm{n}=41, M=2.12$, median $=3.00)$. 
TABLE 20. Catch Related Factors--Restricted Access

\begin{tabular}{lcc} 
& Mean & Median \\
\hline Total Number of Fish Caught Per Hour $(n=51)$ & .94 & 1.00 \\
Proportion of catch consisting of rainbow trout & .49 & .00 \\
that are greater than 20" $(n=41)$ & 1.51 & 2.00 \\
Size of largest trout caught $(n=41)$ & 1.40 & 2.00 \\
Variety of species caught $(n=42)$ & 2.12 & 3.00 \\
Color and health of rainbow trout caught & $(n=41)$ & \\
\hline
\end{tabular}

Note: The total number of respondents may vary due to missing data.

\section{Time Spent Angling}

Anglers were asked to report the total amount of time (in minutes) they spent angling (Tables 21-23) during their visit. At Pipestem Resort State Park, the mean time spent fishing was 405.57 minutes $(n=84)$, where open access anglers $(n=43)$ spent an average of 228.60 minutes angling, and package anglers $(\mathrm{n}=41)$ spent over twice as much time angling with an average of 591.17 minutes. This can partially be explained by the fact that open access anglers were only there during a one day period, and package anglers stayed overnight at the resort. Anglers at Harman's North Fork Cottages $(n=53)$ spent an average of 508.11 minutes angling. Of all anglers participating in this study, only the tournament anglers $(n=18)$ were all given the same fishing time limits (i.e., 360 minutes). Overnight guests at both resorts reported the same amount of time spent angling-- 508.11 minutes at Harman's and 591.17 minutes at Pipestem Resort State Park. One possibility that can explain this small difference is that at Pipestem Resort State Park, the activities and fishing are structured around the guide and outfitter services whereas at Harman's North Fork Cottages, the amount of angling that takes place is based solely on the individual's desire to fish. 
TABLE 21. Minutes Spent Angling

\begin{tabular}{lcc} 
& Mean & Median \\
\hline Open Access $(n=84)$ & 405.57 & 300 \\
Restricted Access $(n=53)$ & 508.11 & 360 \\
\hline
\end{tabular}

Note: Total number of respondents may vary due to missing data.

TABLE 22. Minutes Spent Angling - Open Access

\begin{tabular}{lcc} 
& Mean & Median \\
\hline Open Access Anglers & 228.60 & 180 \\
$(n=43)$ & 591.17 & 480 \\
\hline
\end{tabular}

Note: Total number of respondents may vary due to missing data.

\section{Catch Per Unit Effort}

The Catch Per Unit Effort (CPUE) has be defined by the number of fish caught per hour.

This is a standardized method of comparing the success rates of anglers across the groups (Table

23). As a whole $(n=135)$ the mean Catch Per Unit Effort was 1.11 fish/hour. At public access $(\mathrm{n}=84)$, the CPUE was slightly higher at 1.35 fish/hour and private access anglers $(\mathrm{n}=51)$ had a lower CPUE at .72 fish/hour. To investigate the specialization of fisherman (Table 24) the results were broken up into the four specific user groups. The Open Access Unguided Anglers ( $\mathrm{n}=43$ ) had the highest CPUE at 1.74 fish/hour, followed by the HNFC Tournament Anglers $(n=18)$ with .98 fish/hour, then followed closely by Open Access Guided Anglers ( $n=41)$ with a CPUE of .94 fish/per hour. Lastly, Restricted Access Unguided Anglers (n=33) had an average CPUE of .57 fish/hour. Not surprisingly are these results, as the open access anglers tended to be locals who have repeat visits and therefore more knowledge of the stream and the fish behavior. The tournament anglers fish competitively as their specialization which is an advantage they hold over the unguided anglers. Also, like the Open Access - Unguided Anglers and Restricted Access - Tournament Anglers, those on the guided trip while they may lack some of the skill the presence and assistance of a guide improves their success rates. 
TABLE 23. Catch Per Unit Effort --Venue

\begin{tabular}{|c|c|c|}
\hline & Mean & Median \\
\hline All Anglers $(n=135)$ & 1.11 & .67 \\
\hline $\begin{array}{l}\text { Pipestem Resort State } \\
\text { Park }(n=84)\end{array}$ & 1.35 & 1.0 \\
\hline $\begin{array}{l}\text { Harman's North } \\
\text { Fork Cottages } \\
(n=51)\end{array}$ & .72 & .44 \\
\hline \multicolumn{3}{|c|}{ Note: Total number of respondents may vary due to missing data. } \\
\hline & Mean & Median \\
\hline $\begin{array}{l}\text { Open Access - Unguided } \\
\text { Anglers }(n=43)\end{array}$ & 1.74 & 1.20 \\
\hline $\begin{array}{l}\text { Open Access }- \text { Guided } \\
\text { Anglers }(n=41)\end{array}$ & .94 & .55 \\
\hline $\begin{array}{l}\text { Restricted Access - } \\
\text { Unguided Angler }(n=33)\end{array}$ & .57 & .32 \\
\hline \multicolumn{3}{|l|}{ Restricted Access } \\
\hline $\begin{array}{l}\text { Tournament Angler } \\
(n=18)\end{array}$ & .98 & .73 \\
\hline
\end{tabular}

Note: Total number of respondents may vary due to missing data.

\section{Yearly Fishing Equipment Expenditures}

Specialization in the sport involves the expenditure of additional gear, licenses, and other angling related goods. Respondents were asked how much they spent in the past year on their fishing supplies (Table 25). For all anglers $(n=129)$, mean gear expenditures was 827.24 dollars in the past year. When broken into the four user groups defined, the HNFC tournament anglers $(n=18)$ had the highest gear expenditure annually at 2,980.57 dollars. This group had one professional angler report spending $\$ 30,000$ in the past year on fishing supplies (a bass boat) which is much higher than many of the other anglers, even in that category. This group skewed the average to the right for the remaining groups and overall mean. Non-tournament anglers at Harman's $(n=33)$ reported expenditures were 537.12 dollars in the past year, followed by Open Access Unguided Anglers (n=42) with 482.36 dollars, and Open Access Guided Anglers ( $\mathrm{n}=36$ ) 
with 418.89 dollars.

TABLE 25. Expenditures on Gear (USD\$) Annually

\begin{tabular}{lcc} 
& & Mean \\
\hline All Anglers $(n=129)$ & 827.24 & Range \\
Open Access - Unguided Anglers $(n=42)$ & 482.36 & $20-5,000$ \\
Open Access - Guided Anglers $(n=36)$ & 418.89 & $0-5,000$ \\
Restricted Access - Unguided Angler $(n=33)$ & 537.12 & $0-30,000$ \\
Restricted Access - Guided Angler $(n=18)$ & 2980.56 & $0-30,000$ \\
\hline
\end{tabular}

Note: Total number of respondents may vary due to missing data.

\section{Comparing Variables Associated with Quality Fishing Experiences}

Table 26 reports the mean scores of the nine variables associated with quality fee fishing experiences. Five of these variables are the catch related factors posed to each angler, and the additional four include CPUE, quality of experience, total trip expenditure, and the willingness to pay (total value of the trip).

To determine if there was a statistical difference between the four groups, an analysis of variance was conducted. Of all the variables, four were found to be statistically significant $(\alpha=.05)$. CPUE, Total Trip Expenditure, Willingness to Pay, and Variety of Species Caught differed significantly by fishing venue (Sheffé's post hoc, $p=.02$ ). Mean scores for the variable, Variety of species caught were significantly more acceptable for Tournament Anglers (1.78) than Open Access Anglers (1.48) and and Guided Package Anglers (.36), and no statistical difference was noted for Private Access Anglers (1.17) ( $\alpha=.10)$. This variable was measured on a scale from -3 (very dissatisfied) to +3 (very satisfied), reflecting that Open Access and Tournament Anglers were statistically more satisfied with the quality of the fish caught than the Guided Package Anglers. CPUE mean scores were found to be significantly different where reported catch rates for the Open Access Anglers (1.74) were greater than Guided Package Anglers (.94) and Private Access (.36). Not statistical difference was noted for Tournament Anglers (.98). The 
last two variables were significant at an alpha level of .05 and include Total Trip Expenditures and Willingness to Pay. For Total Trip Expenditures, the mean scores for Tournament Anglers (855.91) were reported to be greater than Open Access (181.48) and Private Access (261.27) with no noted difference for Guided Package (530.18). The variable, Willingness to Pay is calculated Total Trip Expenditure plus the additional amount participant's are willing to pay for the same experience in the future. Similar to Total Trip Expenditure, Tournament Anglers (1375.00) were found to have a significantly higher willingness to pay than Open Access (243.61) anglers. There was no significant difference found for the Guided Package (596.85) and Private Access (487.82). 
TABLE 26. ANOVA of Catch Related Factors by Fishing Venue.

\begin{tabular}{|c|c|c|c|c|c|c|c|}
\hline Indicator & $\begin{array}{c}\text { Open } \\
\text { Access } \\
\text { Unguided } \\
\text { (a) }\end{array}$ & $\begin{array}{l}\text { Open } \\
\text { Access } \\
\text { Guided } \\
\text { (b) } \\
\end{array}$ & $\begin{array}{l}\text { Private } \\
\text { Access } \\
\text { Unguided } \\
\text { (c) }\end{array}$ & $\begin{array}{l}\text { Private } \\
\text { Access } \\
\text { Invitation } \\
\text { (d) }\end{array}$ & $F(d f)$ & $\mathrm{p}$ & $\begin{array}{c}\text { Sheffé's } \\
\text { post } \\
\text { hoc }\end{array}$ \\
\hline $\begin{array}{l}\text { Total number of } \\
\text { fish caught per } \\
\text { hour }^{1}\end{array}$ & 1.58 & .66 & .67 & 1.44 & $2.50(3,125)$ & .06 & --- \\
\hline $\begin{array}{l}\text { Proportion of } \\
\text { Catch consisting } \\
\text { of rainbow trout } \\
\text { that are greater } \\
\text { than } 20,1\end{array}$ & .37 & .59 & .63 & .29 & $.16(3,112)$ & .93 & --- \\
\hline $\begin{array}{l}\text { Size of largest } \\
\text { trout caught }\end{array}$ & 1.69 & 1.58 & 1.35 & 1.72 & $.27(3,105)$ & .85 & --- \\
\hline $\begin{array}{l}\text { Variety of species } \\
\text { caught }{ }^{1}\end{array}$ & 1.48 & .36 & 1.17 & 1.72 & $3.57(3,111)$ & .02 & $\mathrm{~b}<\mathrm{a}, \mathrm{d}^{* *}$ \\
\hline $\begin{array}{l}\text { Color and health } \\
\text { of rainbow trout } \\
\text { caught }^{1}\end{array}$ & 2.22 & 2.07 & 2.39 & 1.78 & $.76(3,104)$ & .52 & --- \\
\hline $\begin{array}{l}\text { Quality of } \\
\text { Experience }^{2}\end{array}$ & 6.02 & 6.05 & 5.85 & 5.53 & $.94(3,127)$ & .42 & --- \\
\hline $\mathrm{CPUE}^{3}$ & 1.74 & .94 & .36 & .98 & $5.97(3,131)$ & $<.01$ & $a>b, c^{*}$ \\
\hline $\begin{array}{l}\text { Total Trip } \\
\text { Expenditure }^{4}\end{array}$ & 181.48 & 530.18 & 261.27 & 855.91 & $6.74(3.110)$ & $<.01$ & $\mathrm{~d}>\mathrm{a}, \mathrm{c}^{*}$ \\
\hline $\begin{array}{l}\text { Willingness to } \\
\text { Pay }\end{array}$ & 243.61 & 596.86 & 487.82 & 1375.00 & $8.55(3,71)$ & $<.01$ & $\mathrm{~d}>\mathrm{a}^{*}$ \\
\hline \multicolumn{8}{|c|}{$\begin{array}{l}\text { Note: } \\
1 \text { Represents a scale of }-3 \text { (Very Unacceptable) to }+3 \text { (Very Acceptable). } \\
2 \text { Represents a scale of } 1 \text { (Poor) to } 7 \text { (Excellent). } \\
3 \text { Represents the Catch Per Unit Effort in terms of fish caught per hour. } \\
4 \text { Represents the respondents cost for their fishing trip. } \\
5 \text { Represents the respondents cost for their trip and any additional willingness to pay for those } \\
\quad \text { services. } \\
\begin{array}{ll}* \alpha=.05 \\
* * \alpha=.10\end{array}\end{array}$} \\
\hline
\end{tabular}


Several other methods of catch related success were measured, including largest rainbow trout landed, the number of twenty inches or greater rainbow trout, and the total number of fish caught during the visit are reported in Table 27. Significance was found at the alpha level of .05 for largest fish landed $(\mathrm{p}=.03)$. The private access-tournament anglers' largest trout landed was 19.20 inches, significantly higher than that of the open access-guided angler (13.39 inches). No differences were reported for the open access-unguided angler (16.33 inches) and the private access-unguided angler (17.53). For the number of fish caught greater than twenty inches, open access-guided anglers reported 1.44 fish, private access-tournament anglers reported .72 fish, open access-unguided reported .51 fish, and private access-unguided reported .48 fish. Let it be noted that in Table 26, there is no reported differences in the acceptability for these sizes of fish (Catch related factors $2 \& 3$, respectively). Total number of fish caught per trip by the angler was highest in the open access-guided anglers (7.66) followed by the open access-unguided anglers (6.86), the private access-tournament anglers (5.50) and the private access-unguided anglers (5.39).

TABLE 27. ANOVA Other Measures of Catch Success by Fishing Venue

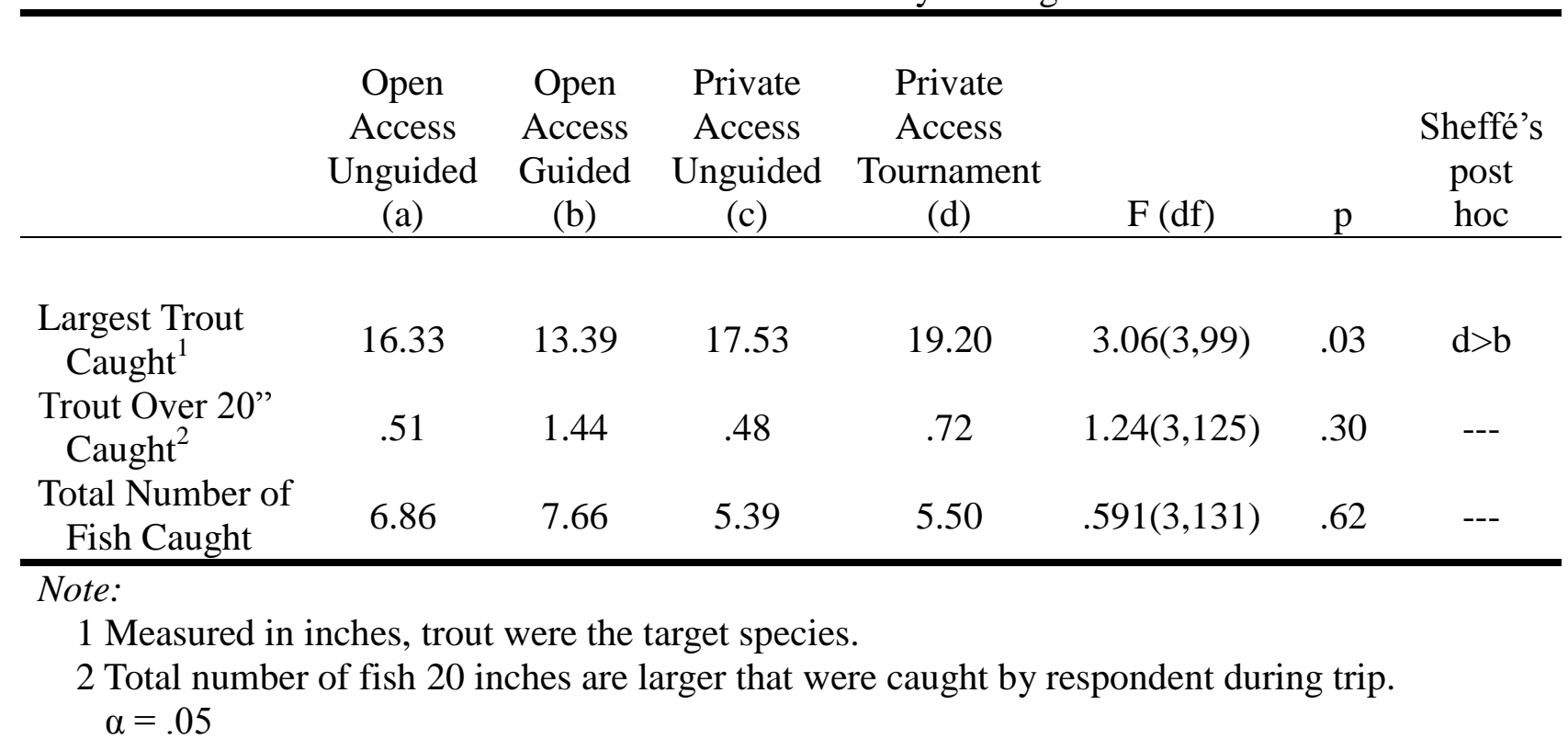


Table 28 shows that there is a statistical difference the number of open access guided and unguided anglers. The proportion of new unguided visitors was 9 percent and the proportion of new guided visitors was 57 percent which was found to be significant $(\alpha=.05)$. No significant statistical differences were found for the private access site. Stocking awareness was also measured and found to be significant. The level of awareness of the open access-unguided angler $(60 \%)$ was found to be significantly lower than that of the private access-unguided angler (94\%) and private access-tournament angler (97\%), and no statistical significance was found with the awareness of the open access-guided angler (73\%).

Figure 11 depicts the development of a normative curve in regards to catch rates of the different fishing venues. This is truly evident in the Open Access-Unguided Anglers. Noted acceptability of catch rate differs amongst the groups, where the preferred catch rates of both segments of the Open Access site have CPUE preferences nearing two fish per hour, with a minimally acceptable level closer to one fish per hour. For the private access segment, preferred catch rates are slightly lower with a preference of between one and one and a half fish per hour, and a minimally acceptable condition only slightly higher than zero. While these catch rates reflect more of the management goals noted by Miko et al. (1994), it is not indicative that catch rates at private access sites do not need to be maintained at as high of a level it points more towards the open access anglers have a greater desire to more fish which in turn placed greater strain on public fisheries. The expectations of angler catch rates were not examined in this study. This research project intended to serve as a program evaluation of four different fishing venues that utilized different stocking strategies along a spectrum of access. 
TABLE 28. ANOVA of Site Visitation and Motivation by Fishing Venue.

\begin{tabular}{|c|c|c|c|c|c|c|c|}
\hline & $\begin{array}{c}\text { Open } \\
\text { Access } \\
\text { Unguided } \\
\text { (a) }\end{array}$ & $\begin{array}{c}\text { Open } \\
\text { Access } \\
\text { Guided } \\
\text { (b) }\end{array}$ & $\begin{array}{c}\text { Private } \\
\text { Access } \\
\text { Unguided } \\
\text { (c) } \\
\end{array}$ & $\begin{array}{c}\text { Private } \\
\text { Access } \\
\text { Tournament } \\
\text { (d) }\end{array}$ & $\mathrm{F}(\mathrm{df})$ & $\mathrm{p}$ & $\begin{array}{c}\text { Sheffé's } \\
\text { post } \\
\text { hoc }\end{array}$ \\
\hline $\begin{array}{l}\text { First Time } \\
\text { Visitor }\end{array}$ & $9 \%$ & $57 \%$ & $27 \%$ & $50 \%$ & $9.64(3,130)$ & $<.01$ & $b>a$ \\
\hline $\begin{array}{l}\text { Fishing as a } \\
\text { Motivation }^{1}\end{array}$ & $88.16 \%$ & $89.25 \%$ & $85.15 \%$ & $86.47 \%$ & $.96(3,129)$ & .41 & --- \\
\hline $\begin{array}{l}\text { Stocking } \\
\text { Awareness }\end{array}$ & $60 \%$ & $73 \%$ & $94 \%$ & $97 \%$ & $6.69(3,130)$ & $<.01$ & $\mathrm{c}, \mathrm{d}>\mathrm{a}$ \\
\hline
\end{tabular}

Note:

1 Fishing as a motivation for visiting a site (measured as a percent from $0 \%$ to 100 $\alpha=.05$

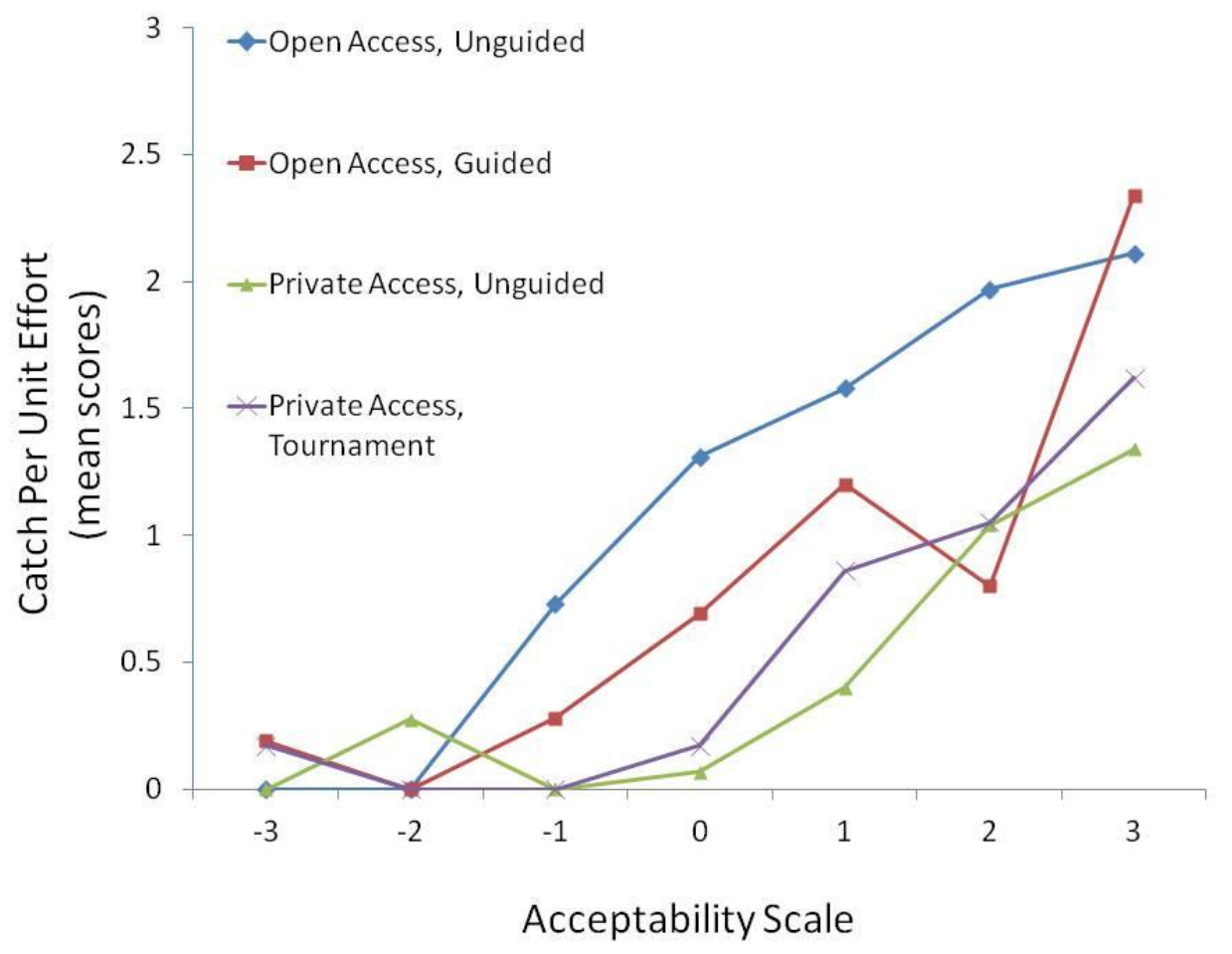

Figure 11. Development of Catch Rate (CPUE) Acceptability Normative Curve 


\section{Analysis of Other Anglers, Crowding, and Influence on Satisfaction}

The reason for the existence of publicly stocked streams is to reduce the number of anglers fishing on the stream to increase catch rates. Table 29 reports the number of other anglers reported to be fishing on the stream as well as the acceptability of those anglers to the respondent. Of the anglers that were surveyed, the private access, unguided group reported a statistically higher number of other anglers fishing on the property $(M=9.67)$ than both the open access unguided group $(M=5.30)$ and the open access guided $(M=6.66)$. The acceptability of encounters with other anglers on the stream did not differ among fishing venues. However, private access, unguided reported the lowest acceptability of all groups $(M=161)$. Both private access groups reported higher acceptability of encounters with other anglers than the public access anglers.

TABLE 29. ANOVA of Crowding Perceptions by Fishing Venue.

\begin{tabular}{|c|c|c|c|c|c|c|c|}
\hline & $\begin{array}{c}\text { Open } \\
\text { Access } \\
\text { Unguided } \\
\text { (a) }\end{array}$ & $\begin{array}{c}\text { Open } \\
\text { Access } \\
\text { Guided } \\
\text { (b) }\end{array}$ & $\begin{array}{c}\text { Private } \\
\text { Access } \\
\text { Unguided } \\
\text { (c) }\end{array}$ & $\begin{array}{l}\text { Private } \\
\text { Access } \\
\text { Invitation } \\
\text { (d) }\end{array}$ & $F(d f)$ & $\mathrm{p}$ & $\begin{array}{c}\text { Sheffé's } \\
\text { post } \\
\text { hoc }\end{array}$ \\
\hline $\begin{array}{l}\text { Other Anglers } \\
\text { Seen Fishing }\end{array}$ & 5.30 & 6.66 & 9.67 & 7.88 & $6.33(3,130)$ & $<.01$ & $c>a, b$ \\
\hline $\begin{array}{l}\text { Acceptability of } \\
\text { Other Anglers }\end{array}$ & 2.23 & 2.12 & 1.61 & 2.35 & $2.00(3,130)$ & .117 & --- \\
\hline
\end{tabular}

\section{Regression Model for Catch Per Unit Effort}

In Table 30, the relationships between access, age, gender, first time visit, and annual gear expenditures (specialization) on the CPUE is explained. The model shows significance with $\mathrm{p}$ value of .005 , yet only achieved an adjusted $\mathrm{R}^{2}$ value of .103 . Open access was the strongest predictor of CPUE $(B=.355, p=.014)$ and the only one of significance. Of the other independent 
variables, age was found to be a negative predictor $(\mathrm{B}=-.136, \mathrm{p}=.122)$ was reported, as well as some positive relationshionship in specialization $(B=.118, p=.198)$, although neither were significant. The remaining variables were neither significant nor had much weight in the model.

Table 29. Regression Estimates for Catch Success (CPUE)

\begin{tabular}{lcccccc}
\hline & Beta & t-Statistic & F-Statistic & p-value & Adj. R $^{2}$ & df \\
\hline CPUE Model & & & $\mathbf{3 . 0 6 2}$ & $\mathbf{. 0 0 5}$ & $\mathbf{. 1 0 3}$ & $\mathbf{1 2 6}$ \\
Open Access - Unguided Angler & .355 & 2.504 & & .014 & & \\
Open Access - Guided Angler & .092 & .674 & & .501 & & \\
Restricted Access - Unguided & -.063 & -.474 & & .637 & \\
$\quad$ Angler & -.136 & -1.559 & & .122 & \\
Age & -.045 & -.517 & & .606 & \\
Gender & .054 & .570 & & .570 & \\
First Visit & .118 & 1.294 & & .198 & \\
Annual Gear Expenditure &
\end{tabular}

Note: Restricted Access - Tournament Anglers were excluded from this regression as they were determined to be different than traditional guided and unguided anglers. 


\section{$\underline{\text { Introduction }}$}

CHAPTER 5

DISCUSSION, CONCLUSION, and RECOMMENDATIONS

This study was part of a larger study and program evaluation. The study used both data collected previously at a West Virginia University sponsored stocking project at Pipestem Resort State Park, as well as new data collected from Harman's North Fork Cottages to add to and diversify the data collected. The additional HNFC data collected allowed for additional depth and to understand the varying levels of access restriction that exists and how it may affect the overall quality of the experience.

\section{$\underline{\text { Summary of Findings }}$}

The anglers, as well as non-anglers, that participated in the study were diverse in terms of annual income, group type, and trip/angling related expenditures. Participants were predominantly Caucasian males. Of all the participants, nearly two thirds were returning guests to their destination.

Catch Per Unit Effort scores varied amongst the different angling groups, as well as across the different economic classes. Across the groups, it seems that knowledge plays a factor in fishing success. The highest CPUE were recorded with drop-in anglers at Pipestem Resort State Park or Open Access anglers, followed by the Tournament Anglers whom were not found to be statistically different. Guided package anglers and the Private Access anglers were found to have significantly lower CPUE mean scores, which may be the result of several factors. Further investigation through a regression model showed that Open Access-Unguided Anglers showed the only significant predictor of CPUE. However, it is difficult to say that there may be a relationship because factors such as turbidity and flow, which were noted to be different between the venues and seasons, was not recorded due to these factors not being manageable or 
repeatable events which are requirements of good indicators of quality fishing experiences.

The number of individuals seen fishing the stream by the angler was significantly higher at the private venue than at the public venue, and the acceptability of the number of anglers fishing along that stream reflected these mean scores, as acceptability was lowest where the number of anglers seen fishing was the highest.

\section{$\underline{\text { Limitations and Delimitations }}$}

Data collection was limited to the trout fishing season(s): spring and fall. We also limited data collection to the busiest days of the week (primarily Friday-Sunday) due to limited resources to conduct the study.

This study did not control for several variables that can contribute to fishing success and trip enjoyment. The study did not control for weather conditions that were experienced by anglers during their visit. The style of trout fishing (e.g., fly fishing, spin fishing, shore fishing, and wading), equipment used (e.g., fly tackle and spinning tackle), and type of bait or lures used were not controlled. Although one measure of visitor use history and one measure of activity specialization were included in the study, they were not used as blocking factors in the analysis. All of these variables may play important role in defining norm curves for catch-rate and the number of encounters with other anglers, as well as the overall quality of visitor experience.

This study is a program evaluation. The research was conducted to evaluate four different fishing venues along a spectrum of access. Each venue serves as a unique benchmark and the data collected provides a baseline for future research.

\section{Theoretical Implications}

This study did not control for access. Instead, study sites were chosen specifically so that sites displayed a gradient of access along the spectrum. It would be of further important to study 
the entire spectrum of access through experimental design. What can be drawn from this study is some inferences on the role that restricting access has on the participant. No statistical difference was reported in the overall satisfaction hypothesized to be of importance for anglers seeking a premium fishing experience. Catch Per Unit Effort values were found to be significantly different for some of the groups, however increased restriction did not equate to higher catch rates or satisfaction.

What seems to be occurring within the realm of controlling access is that the program formats are more complex than simply an open access or closed access environment. These different formats seem to attract different levels of specialization within the participant pool. In a future study, the level of specialization should be recorded to examine any correlation between those variables, catch rates, and overall angler satisfaction. While it was not recorded as part of the study, it was observed by the survey collectors that the method used differed between the groups. Both unguided study groups were a mix of both spinning and fly fishing gear during their visits. For the guided anglers, a group with the lowest overall CPUE, fly fishing equipment was the predominant method of angling. Many individuals in this group were taught by their provided guide streamside how to fly fish. All anglers in the tournament group were fly rod anglers, as per the requirements of the tournament sponsor. What this presents here is varying levels of skill and specialization between the groups.

The Normative Curve that was created by graphing the mean scores for CPUE with their respective levels of acceptability suggests that these different groups of anglers have different preferred levels of catch rate. Open Access Unguided Anglers prefer higher catch rates, and their minimally acceptable conditions are near equivalent to the preferred conditions of the private access unguided anglers. What this may mean for managers is that stocking for a desired catch 
rate is only relevant for the type of angler fishing the stream. Coping behaviors and other mechanisms may be in play for the private access anglers which may explain why they are willing to accept the lower catch rates. Because this study did not measure angler expectations, it is impossible to say if the anglers were satisfied with their catch rates due to their expectations being met. What was recorded within this study is an overall high level of satisfaction reported by all angler groups.

\section{Future Research Implications}

A future study would need to employ a higher level of experimental design control than this one. Ideally, that study would control for access, specialization, and skill level. In our study, we were not able to control for such factors, so therefore drawing conclusions from the data would be difficult. The open access-unguided anglers had higher catch rates than any of the other user groups, which was surprising due to the reason for the creation of controlled access, non-governmental stream fishing opportunities was to provide a venue that offered higher catch rates. The skill and specialization level of each group needs to be investigated to understand how it plays a role in the dynamics of user satisfaction and overall trip experience.

Controlling for access, specialization, and skill level is difficult. While the groups used in this study were self selected and it seems that some skill level or specialization may be estimated through annual gear expenditures, what should be asked in a future study should be years of experience, annual fishing outings, as well as an official record of the method (spinning vs. fly rod) used during the angling experience.

\section{Management Implications}

\section{To Manage Fee Fishing Streams}

As previously discussed, the existence of fee fishing operations, such as Pipestem Resort 
State Park and Harman's North Fork Cottages, is to provide a quality experience and service that the Department of Natural Resources is unable to provide on publicly stocked streams due to factors such as crowding, poaching, and truck following. With that being said, the resorts must manage their fish populations at healthy levels to maintain the quality of the experience. Fish stocking an investment, and comes with several risks. Many of these risks are difficult to manage, such as drought and high water events or water contamination from sources beyond their property.

The stocking of fish is an investment, and being so, it should be done wisely. Using implications gathered from catch related data, specifically looking at CPUE information and Catch Related Factor 1: Total Number of Fish Caught Per Hour can help determine a manageable level of fish stocking that is appropriate and provides individuals with the satisfactory experience that they desire. With Moldovanyi et. al (2004) the desired catch rates for anglers was two fish per hour. With each of the respective groups, it was the open access on public land that came the closest to reporting those values with a CPUE of 1.74 which was found to be significantly greater than both the guided angler on public land (.94) and the non-guided angler on private land(.36) at an alpha level of .05. While no significance was found to exist between the mean scores of quality of experience for the different groups, the mean scores on public land were greater than those on private land.

What seems to be apparent in this spectrum of access is that restrictions and management for higher catch rates are not having an effect on the total quality of the experience, but instead there are other factors involving all of the services and experiences provided by a site that cause satisfaction. In this study, we did not control for access but drew a comparison of formats along a spectrum. What originally existed at the two study sites were two different program formats, 
unguided anglers on public land and unguided anglers on private land. Through the use of restricting access and changing management policies, the number of program formats doubled at each site creating two new venues that then created a pull to different user groups.

These new groups brought different users. For Pipestem Resort State Park, creating a package of angling and lodging, it brought in new users from farther away who spent more money at their destination. These anglers had different expectations and skill levels, as reflected by CPUE, but were accepting of these lower CPUEs during their visit due to other factors not examined by this study. At Harman's North Fork Cottages, the creation of a fly fishing tournament had similar results. Individuals traveled from increased distances and paid more money for their experience at the resort simply for the opportunity to compete in the invitational only tournament. For managers of both sites, as well as managers of other public and private fishing venues, changing the program format of the services offered instead of changing the resource can attract new user groups to the site. These different groups have different levels of acceptability for catch rates, willingness to pay, and level of specialization within their activity.

Since the start of this study, certain changes have occurred at both sites. Pipestem Resort State Park did not always stock fish in the stream and therefore did not actively manage for the "premium experience". After the institution of the package angling program that provides a guide to paying guests of the resort, the management of the park made several changes to improve that experience. The length of the tram access season was shortened, thus reducing the number of non-guided anglers that would fish the stream. These dates coincide with the time of the season that the packages are offered. While this does not completely close access for the public to reach the stream, without an operational tram, the ability to reach access the stream is hampered by the rugged terrain of the river's gorge. This therefore reduces the number of 
individuals fishing on the stream for the paying participants to achieve their desired experience and minimize conflicts. Delayed harvest measures were also put into place for the park, so that during the season for the package anglers, there would be no harvesting by any individual from either group so that the levels of fish available to be caught were present in the stream.

At Harman's North Fork Cottages, this study has provided implications on management of the stream for providing the premium fishing experience. The information on CPUE and CPUE acceptability will be used by the managers for the better management of stream stocking.

Both organizations used the Fly Rod Chronicles television show to market their destination to possible participants throughout the country. Once again, the modification of the level of access played a part in why the destinations were marketing themselves. The added guided package to the Pipestem Resort State Park site was what was highlighted and advertised, as well as the invitational tournament at Harman's North Fork Cottages. This series is broadcast throughout the country, thus increasing the reach of both destinations to pull individuals from further distances to their sites for the fishing experiences that they offer.

\section{To Create an Organization}

Creation of a cooperative group that links these restricted access areas together to form a marketing group is not novel, as it has been done elsewhere, but it presents an opportunity in West Virginia. Currently, the development of one such group is underway. The Trout Trail of the Virginias (TTV) is also being developed by Pierskalla and others to serve the needs of both the producers (fee fishing destinations) and consumers (anglers) in a way that is mutually beneficial. In studies by Mei et. al (2006) there were implications drawn that visitors sought destination packing options to plan their vacations. The TTV can serve as the broker for these interactions as well as a knowledge base to provide start up organizations the information needed 
to successfully run a fee fishing operation. Specifically in reaching their target markets and providing the quality of experiences desired by those markets through sufficient fish stocking information. That information can be gathered from this study and similar studies to come on the private fee fishing market, its patrons, and their motivations.

The goal of the TTV is to create a tourism industry based upon quality fee fishing venues in the two states. The overarching goal is to create a tourism destination that is regional, national, and international. The quality streams, tourism providers, and fish producers in this region create a competitive advantage yet to be fully developed.

Out-of-state visitors, locally from Ohio, Pennsylvania, Maryland, Washington D.C., and Kentucky primarily spend money in the states as they visit. Whether the visitors travel from these five states or farther, the money that is spent as they recreate enters Virginia and West Virginia having positive economic benefits to the businesses they patronize and both states. Increases in tourism due to increased marketing for the TTV in these surrounding states, as well as the rest of the country, such as through the use of "Fly Rod Chronicles" Television series to highlight members of the TTV bring visitors from out of state in to fish these destinations. With increased tourism for fishing, the demand for fish also increases trickling down to fish producers, many of which are members of the WVAA. Other local businesses surrounding the TTV members would also benefit due to increased tourism in the region. 


\section{APPENDIX I. Pipestem Resort State Park Survey}

West Virginia University

Recreation, Parks and Tourism Resources
Interview No.

Interviewer

Date___ Time

Weather Cond. \& Temp.

Good morning/afternoon. My name is and I am employed by . Would you be willing to answer a few questions about your fishing experience? It will probably take about 10 minutes. We are studying the effects of a rainbow trout stocking strategy used in this stream. Since programs to improve the quality and quantity of fishing opportunities cost money, we are especially interested in finding out what you pay for fishing. Your opinions will be compared with other people interviewed, and may help improve fish management programs for the river. Your responses are voluntary and confidential. You don't have to answer every question. This is a research study.

1. Agreed to participate

YES (continue with the on-site interview, give the participate a copy of the instrument and ask them to follow along as you read and record his/her responses) NO (thank them anyway and continue with another contact)

2. How much time today did you spend fishing the North Fork of the South Branch of the Potomac River during this trip?

hour(s) _ _ minute(s)

3. How many fish did you catch today on the river during this trip?

4. What species are they, how large are they (range of sizes), and how many did you keep during this trip?

\begin{tabular}{|l|l|l|l|}
\hline List species & Number caught & Number kept & $\begin{array}{l}\text { Range of sizes of } \\
\text { caught fish (in.) }\end{array}$ \\
\hline & & & \\
\hline & & & \\
\hline & & & \\
\hline
\end{tabular}

5. How many rainbow trout did you catch that were greater than 20" (about $4 \mathrm{lbs}$.)?

6. The total number of fish caught, size of fish, and fish color may contribute to the overall fishing experience. Please indicate how ACCEPTABLE each of the following catch-related factors was to your experience while fishing the river during this trip. Please refer to the 7-point scale shown in question 6 when responding, wherein -3 is very unacceptable and +3 is very acceptable.

\begin{tabular}{|c|c|c|c|c|c|c|c|}
\hline \multirow{2}{*}{$\begin{array}{l}\text { Catch-related factors } \\
\text { Total \# of fish caught per hour that you spent fishing } \\
\text { (Note: this includes all species of fish, not just trout) }\end{array}$} & \multicolumn{5}{|c|}{$\begin{array}{l}\text { Very } \\
\text { Unacceptable }\end{array}$} & \multicolumn{2}{|c|}{$\begin{array}{r}\text { Very } \\
\text { Acceptable }\end{array}$} \\
\hline & -3 & -2 & -1 & 0 & +1 & +2 & +3 \\
\hline $\begin{array}{l}\text { Proportion of catch consisting of rainbow trout that } \\
\text { are each greater than } 20 \text { " (or about } 4 \text { lbs.) }\end{array}$ & -3 & -2 & -1 & 0 & +1 & +2 & +3 \\
\hline $\begin{array}{l}\text { Size of largest rainbow trout caught } \\
\text { (Note: leave blank if no trout were caught) }\end{array}$ & -3 & -2 & -1 & 0 & +1 & +2 & +3 \\
\hline Variety of species caught & -3 & -2 & -1 & 0 & +1 & +2 & +3 \\
\hline Color and health of rainbow trout caught & -3 & -2 & -1 & 0 & +1 & +2 & +3 \\
\hline
\end{tabular}

7. What was the maximum number of anglers you saw fishing (at one time) on the river during this trip? Anglers 
8. How acceptable was the maximum number of other people you saw fishing at one time? Please refer to the 7-point scale shown in question 8 when responding, wherein -3 is very unacceptable and +3 is very acceptable.

$$
\begin{array}{ccccccccc}
\text { Very Unacceptable } & & & & \text { Very Acceptable } \\
-3 & -2 & -1 & 0 & +1 & +2 & +3
\end{array}
$$

9. We are interested in understanding the quantity of recreation opportunities or events that you experienced today while fishing the river. Examples of events might include such things as setting a hook, reeling in a fish, taking photographs by the river, walking along the stream, getting caught in bad weather, visiting with family or friends, picnicking by the stream, standing in the water, seeing birds fly overhead, hearing the tram go by, seeing other people fish beside you, reeling in more fish, etc. How eventful would you consider today's fishing experience on the Bluestone River? That is, how much happened during today's fishing experience? Please refer to the 7-point scale provided in question 9

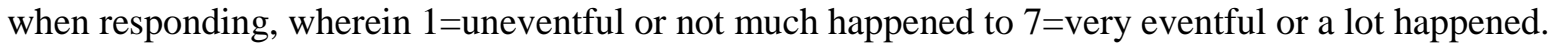

\begin{tabular}{ccccccc}
$\begin{array}{c}\text { Not much happened } \\
\text { (uneventful) }\end{array}$ & \multicolumn{2}{c}{ Moderate } & $\begin{array}{r}\text { A lot happened } \\
\text { (very eventful) }\end{array}$ \\
1 & 2 & 3 & 4 & 5 & 6 & 7
\end{tabular}

10. We are also interested in the overall quality of those different experiences or events you had today while fishing. How do you rate the overall quality of today's fishing experiences on the Bluestone River. Please refer to the 7-point scale provided in question 10 when responding, wherein $1=$ poor quality to $7=$ excellent quality.

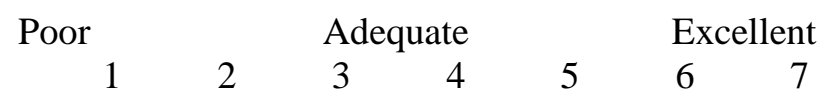

For the next few questions, we will be trying to find out how the overall quality and quantity of those fishing opportunities and events that you just reported affect your maximum willingness to pay for this fishing experience. Please keep in mind this is a hypothetical experiment intended to provide some notion of how strongly you feel about the quality and quantity of fishing opportunities. Assume that the only way to assure yourself of a high quality and eventful recreation experience is through your payment of trip expenses.

11. How many people are in your party with whom some or all of your total trip costs are shared?

12. Please estimate how much money your party will spend at Pipestem Resort including food, accommodations, tram fare, entertainment, etc. \$

13. On a scale from $0 \%$ to $100 \%$, what is your individual share of these within park costs (whether paid by yourself or by someone else for you)? $\%$ equals: $\$$

14. Please estimate how much money your party will spend OUTSIDE the resort during this trip including travel, food, outside park accommodations and entertainment, etc.

$\$$

15. On a scale from $0 \%$ to $100 \%$, what is your individual share of these outside the resort costs (whether paid by yourself or by someone else for you)? $\%$ equals: $\$$

16. Note: Add values reported in 13 and 15. What is the value of your total recreation experience on this 
trip? Is it worth more than the $\$$ (totals from 13 and 15) actually spent on this trip? Yes No

If yes, about how much more is this trip worth? Assume that the trip became more expensive, due perhaps to travel costs or lodging, etc., what is the maximum you would pay for this trip (rather than give it up)? Please refer to the payment card when making a selection. (Present payment card to study participant). \$

17. Did you know the river was stocked with fish prior to this visit? __ Yes _ _ No

18. There are a number of reasons for a visitor to visit Harman's Cabins. On a scale ranging from $0 \%$ to $100 \%$, what degree was fishing the Bluestone River a reason for your visit to the park. (Note: Circle or write in a number below).

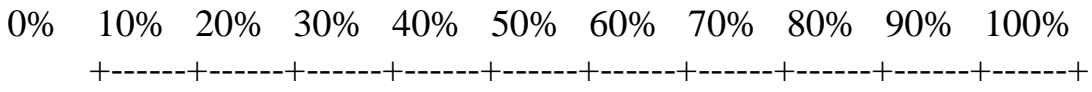

19. If you could not have visited the river today, what other fishing location would you have fished instead?

20. How much money did you spend on fishing equipment (tackle, special cloths, books, maps, fly tying equipment and materials, lure making equipment, etc.) over the last 12 months? \$

The following questions ask for some information about yourself. Your answers will be held confidential and you personally will not be identified in reporting of the results.

21. Gender: _Male Female

22. What year were you born? 19

23. Where do you live?

City State zip code

24. How many road miles from your home is Pipestem State Park, one-way? miles

25. Referring to the list provided in question 25, what type of group were you traveling with on this visit (e.g., family, friends, etc.)?

Alone

A couple Family with children Organized group
Two or more families or relatives together Family and friends Two or more friends together

26. Referring to the list provided in question 26, which of the following best describes your present situation?

Single, no children Married, no children Married with children
Single parent with children

Domestic partnership

Other (please explain)

27. Is this your first visit to Pipestem Resort?

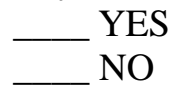

If NO, how many times have you visited this resort during the last 12 months, including this visit? visits

28. How many nights will you be away from home on this trip? nights 
29. How many nights do you plan on spending Harman's Cabins during this trip? nights

30. Referring to the list provided in question 30, which best describes your race or ethnic group Caucasian

Hispanic

African American

_ Native American or Native Alaskan

_ Pacific Islander

_ Asian-American

Other

31. Referring to the list provided in question 31, what letter best represents your household income last year (2009) before taxes?
A._Less than $\$ 20,000$
D. $\$ 60,000$ to $\$ 79,000$
B. $\$ 20,000$ to $\$ 39,000$
E. $\$ 80,000$ to $\$ 99,000$
C. $\$ 40,000$ to $\$ 59,000$
F.__ $\$ 100,000$ or more

32. Is there anything else you would like to tell us about your fishing experience at Pipestem Resort? 


\begin{tabular}{ll} 
APPENDIX II. Harman's North Fork Cottages Onsite Survey \\
West Virginia University & Interview No._- \\
Recreation, Parks and Tourism Resources & Interviewer__ Time_- \\
& Date_- Weather Cond. \& Temp._- \\
\hline
\end{tabular}

Good morning/afternoon. My name is and I am a graduate student at West Virginia University. Would you be willing to answer a few questions about your fishing experience? It will probably take about $\mathbf{1 0}$ minutes. We are studying the effects of a rainbow trout stocking strategy used in this stream. Since programs to improve the quality and quantity of fishing opportunities cost money, we are especially interested in finding out what you pay for fishing. Your opinions will be compared with other people interviewed, and may help improve fish management programs for the river. Your responses are voluntary and confidential. You don't have to answer every question. 1. Agreed to participate

YES (continue with the on-site interview, give the participate a copy of the instrument and ask them to follow along as you read and record his/her responses) NO (thank them anyway and continue with another contact)

2. How much time today did you spend fishing the North Fork of the South Branch of the Potomac River during this trip? hour(s) _ _ minute(s)

3. How many fish did you catch today on the river during this trip?

4. What species are they, how large are they (range of sizes), and how many did you keep during this trip?

\begin{tabular}{|l|l|l|l|}
\hline List species & Number caught & Number kept & $\begin{array}{l}\text { Range of sizes of } \\
\text { caught fish (in.) }\end{array}$ \\
\hline & & & \\
\hline & & & \\
\hline & & & \\
\hline
\end{tabular}

5. How many rainbow trout did you catch that were greater than 20" (about $4 \mathrm{lbs}$.)?

6. The total number of fish caught, size of fish, and fish color may contribute to the overall fishing experience. Please indicate how ACCEPTABLE each of the following catch-related factors was to your experience while fishing the river during this trip. Please refer to the 7-point scale shown in question 6 when responding, wherein -3 is very unacceptable and +3 is very acceptable.

\begin{tabular}{|c|c|c|c|c|c|c|c|}
\hline Catch-related fa & \multicolumn{5}{|c|}{$\begin{array}{l}\text { Very } \\
\text { Unacceptable }\end{array}$} & \multicolumn{2}{|c|}{$\begin{array}{r}\text { Very } \\
\text { Acceptable }\end{array}$} \\
\hline $\begin{array}{l}\text { Total \# of fish caught per hour that you spent fishing } \\
\text { (Note: this includes all species of fish, not just trout) }\end{array}$ & -3 & -2 & -1 & 0 & +1 & +2 & +3 \\
\hline $\begin{array}{l}\text { Proportion of catch consisting of rainbow trout that } \\
\text { are each greater than } 20 \text { " (or about } 4 \mathrm{lbs} \text {.) }\end{array}$ & -3 & -2 & -1 & 0 & +1 & +2 & +3 \\
\hline $\begin{array}{l}\text { Size of largest rainbow trout caught } \\
\text { (Note: leave blank if no trout were caught) }\end{array}$ & -3 & -2 & -1 & 0 & +1 & +2 & +3 \\
\hline Variety of species caught & -3 & -2 & -1 & 0 & +1 & +2 & +3 \\
\hline Color and health of rainbow trout caught & -3 & -2 & -1 & 0 & +1 & +2 & +3 \\
\hline
\end{tabular}

7. What was the maximum number of anglers you saw fishing (at one time) on the river during this trip? Anglers 
8. Did you see other anglers catch fish?

Yes No

9. How acceptable was the maximum number of other people you saw fishing at one time? Please refer to the 7-point scale shown in question 8 when responding, wherein -3 is very unacceptable and +3 is very acceptable.

$$
\begin{array}{ccccccccc}
\text { Very Unacceptable } & & & & \text { Very Acceptable } \\
-3 & -2 & -1 & 0 & +1 & +2 & +3
\end{array}
$$

10. We are interested in understanding the quantity of recreation opportunities or events that you experienced today while fishing the river. Examples of events might include such things as setting a hook, reeling in a fish, taking photographs by the river, walking along the stream, getting caught in bad weather, visiting with family or friends, picnicking by the stream, standing in the water, seeing birds fly overhead, hearing the tram go by, seeing other people fish beside you, reeling in more fish, etc. How eventful would you consider today's fishing experience on the Bluestone River? That is, how much happened during today's fishing experience? Please refer to the 7-point scale provided in question 9 when responding, wherein $1=$ uneventful or not much happened to $7=$ very eventful or a lot happened.

\begin{tabular}{ccccccc}
$\begin{array}{c}\text { Not much happened } \\
\text { (uneventful) }\end{array}$ & \multicolumn{2}{c}{ Moderate } & $\begin{array}{c}\text { A lot happened } \\
\text { (very eventful) }\end{array}$ \\
1 & 2 & 3 & 4 & 5 & 6 & 7
\end{tabular}

11. We are also interested in the overall quality of those different experiences or events you had today while fishing. How do you rate the overall quality of today's fishing experiences on the Bluestone River. Please refer to the 7-point scale provided in question 10 when responding, wherein $1=$ poor quality to $7=$ excellent quality.

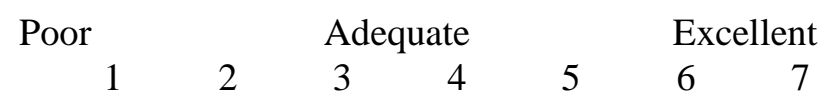

For the next few questions, we will be trying to find out how the overall quality and quantity of those fishing opportunities and events that you just reported affect your maximum willingness to pay for this fishing experience. Please keep in mind this is a hypothetical experiment intended to provide some notion of how strongly you feel about the quality and quantity of fishing opportunities. Assume that the only way to assure yourself of a high quality and eventful recreation experience is through your payment of trip expenses.

12. How many people are in your party with whom some or all of your total trip costs are shared?

13. Please estimate how much money your party will spend at Harman's Cabins including food, accommodations, tram fare, entertainment, etc. \$

14. On a scale from $0 \%$ to $100 \%$, what is your individual share of these within park costs (whether paid by yourself or by someone else for you)? $\%$ equals: $\$$

15. Please estimate how much money your party will spend OUTSIDE the resort during this trip including travel, food, outside park accommodations and entertainment, etc. \$

16. On a scale from $0 \%$ to $100 \%$, what is your individual share of these outside the resort costs (whether paid by yourself or by someone else for you)? $\%$ equals: $\$$ 
17. Note: Add values reported in 14 and 16. What is the value of your total recreation experience on this trip? Is it worth more than the $\$$ No (totals from 13 and 15) actually spent on this trip? __ Yes

If yes, about how much more is this trip worth? Assume that the trip became more expensive, due perhaps to travel costs or lodging, etc., what is the maximum you would pay for this trip (rather than give it up)? Please refer to the payment card when making a selection. (Present payment card to study participant). \$

18. What cabin did you stay in?

19. Did you know the river was stocked with fish prior to this visit? __ Yes _ _ No

20. There are a number of reasons for a visitor to visit Harman's Cabins. On a scale ranging from $0 \%$ to $100 \%$, what degree was fishing the Bluestone River a reason for your visit to the park. (Note: Circle or write in a number below).

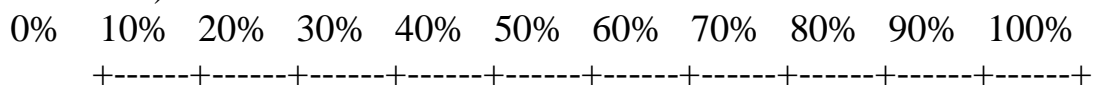

21. If you could not have visited the river today, what other fishing location would you have fished instead?

22. How much money did you spend on fishing equipment (tackle, special cloths, books, maps, fly tying equipment and materials, lure making equipment, etc.) over the last 12 months? \$

23. How ofted did you watch fishing shows or tournaments on television in the last 12 months? I didn't watch any shows/tournaments 5 or less shows/tournaments 6-10 shows/tournaments 11-15 shows/tournaments 16 or more shows/tournaments

\section{The following questions ask for some information about yourself. Your answers will be held} confidential and you personally will not be identified in reporting of the results.

24. Gender: __ Male _Female

25. What year were you born? 19

26. Where do you live? City State zip code

27. How many road miles from your home is Harman's Cabins, one-way? miles

28. Referring to the list provided in question 28, what type of group were you traveling with on this visit (e.g., family, friends, etc.)?

Alone

A couple

Family with children Organized group
Two or more families or relatives together Family and friends Two or more friends together 
29. Referring to the list provided in question 29 , which of the following best describes your present situation?

Single, no children Married, no children Married with children
Single parent with children Domestic partnership Other (please explain)

30. Is this your first visit to Harman's cabins?

YES

If NO, how many times have you visited this resort during the last 12 months, including this visit? visits

31. How many nights will you be away from home on this trip? nights

32. How many nights do you plan on spending Harman's Cabins during this trip? nights

33. Referring to the list provided in question 30 , which best describes your race or ethnic group

Caucasian
Hispanic
African American
Native American or Native Alaskan
Pacific Islander
Asian-American
Other

34. Referring to the list provided in question 31, what letter best represents your household income last year (2010) before taxes?
A.__ Less than $\$ 20,000$
D.___ $\$ 60,000$ to $\$ 79,000$
B.__ $\$ 20,000$ to $\$ 39,000$
E._— $\$ 80,000$ to $\$ 99,000$
C.__ $\$ 40,000$ to $\$ 59,000$
F.__ $\$ 100,000$ or more

35. Is there anything else you would like to tell us about your fishing experience at Harman's Cabins? 


\section{LIST OF REFERENCES}

Azjen, I., and M. Fishbein. 19808. Understanding Attitudes and Prediction Social Behavior. Englwould Cliffs, NJ: Prentice-Hall.

Brunson, M., B. Shelby., and J. Goodwin. 1992. Matching Impacts with Standards in the Design of Wilderness Permit Systems. Defining Wilderness Quality: The Role of Standards in Wilderness Management - A Workshop Proceedings, USDA Forest Service General Technical Report PNW-305,101-6.

Burns, R.C. (2000). Methodological issues associated with customer satisfaction measurement and market segmentation at water-based recreation areas. Unpublished doctoral dissertation, The Pennsylvania State University.

Burns, R.C., Graefe, A.R., \& Absher, J.D. (2003). Alternative measurement approaches to recreational customer satisfaction: Satisfaction -only versus gap scores. Leisure Sciences, $25,1-18$.

Butler, R. L., and D. P. Borgeson. 1965. California "catchable" trout fisheries. Fish Bulletin 127 The California Department of Fish and Game: Sacramento, California, U.S.A.

Cantrell, R.N., Garcia, M., Leung, P.-S. \& Ziemann, D. (2004). Recreational anglers' willingness to pay for increased catch rates of Pacific threadfin (Polydactylus sexfilis) in Hawaii. Fisheries Research, 68 (2004) 149-158.

Cialdani, R.B., C.A. Kallgren, and R.R. Reno, 1991. A Focus Theory of Normative Conduct: A Theoretical Refinement and Reevaluation of the Role of Norms in Human Behavior. Advances in Experimental Social Psychology 24:201-34

Cialdani, R.B., R. R. Reno, and C. A. Kallgren, 1990. A Focus Theory of Normative Conduct: Recycling the Concept of Norms to Reduce Littering in Public Places. Journal of Personality and Social Psychology 58:1015-26

Cichara, C.E. (1982). Fee fishing in Florida. Florida Cooperative Extension Service. Circular 809.

Gainesville, FL: University of Florida

Cronin, J. J., \& Taylor, S. A. (1994). SERVPERF versus SERVQUAL: Reconciling performance-based and perceptions-minus-expectations measurement of service quality. Journal of Marketing, 58(1), 125-131.

Dann, G. M. S. (1977). Anomie, Ego-enhancement and Tourism. Annals of Tourism Research, 5(4), 184-194

Dann, G. M. (1981). Tourism Motivations: An appraisal. Annals of Tourism Research, 8(2), 189219 
Dasman, R. 1964. Wildlife Biology. New York: John Wiley and Sons.

Ellis, G. D., \& Rossman, R. J. (2008`). Creating value for participants through experience staging: Parks, recreation, and tourism in the experience industry.Journal of Park \& Recreation Administration,26(1), 1-20.

Fields J., Pierskalla, C. D., Schuett, M., \& DeCarlo, K. (2004). Determining Demand and Describing a New Market Segment: Hybrid Bluegill and Recreational Pay Fishing. Poster presented at WV Aquaculture Forum, 2004. Available at http://www.wvu.edu/ agexten/aquaculture/2004forum/Fields.pdf . Accessed on April 23, 2007.

Finn, K.L., \& Loomis, D.K. (2001). The importance of catch motives to recreational anglers: the effects of catch satiation and deprivation. Human Dimensions of Wildlife, 6, 173-187.

Fishbein, M. and I. Ajzen. 1975. Belief, Attitude, Intention and Behavior: An Introduction to Theory and Research. Reading, MA: Addison-Wesley.

Graefe, A.R. (1986). Situational and subjective determinants of satisfaction in marine recreational fishing. Leisure Sciences, 8(3), 275-295.

Gronroos, C. (1982). Seven areas of research according to the Nordic school of service marketing. In L. Berry, G. Shostack, \& Upah (Eds.), Emerging perspectives on services marketing (pp. 108-110). Chicago: American Marketing Association.

Hansen, E., Collins, A., Zegre, S., \& Hereford, A. Downstream Strategies, Maryland State Water Quality Advisory Committee (2010). The benefits of acid main drainage remediation on the North Branch Potomac River. Morgantown: Downstream Strategies.

Hardin, G. 1968. The Tragedy of the Commons. Science, 162:1243-48.

Holbrook, M. G. (2000). The millennial consumer in the text of our times: experience and entertainment. Journal of Macromarketing, 20, 178-192.

Jackson, J. M. 1965. Structural Characteristics of Norms. Current Studies in Social Psychology, I.D. Steiner and M. F. Fishbein, eds. New York: Holt, Reinhart \& Winston, 301-309.

Johnson, D.M., and R.G. Walsh (1987). Economic Benefits and Costs of Fish Stocking Program at Blue Mesa Reservoir, Colorado. Technical Report 49, Colorado Water Resources Institute, Fort Collins, Colorado. Cited from Cantrell, R.N., Garcia, M., Leung, P.-S. \& Ziemann, D. (2004). Recreational anglers' willingness to pay for increased catch rates of Pacific threadfin (Polydactylus sexfilis) in Hawaii. Fisheries Research, 68 (2004) 149158.

Johnson, D.M., and R.G. Walsh (1989). Effects of participant skill on the value of alternative 
fishery management practices, in Transactions of the 54th North American Wildlife and Natural Resource Conference, p. 247-254, Wildlife Management Institute, Washington, D.C. Cited from Harpman D.A., Sparling E.W., and T.J. Waddle (1993). A Methodology for Quantifying and Valuing the Impacts of Flow Changes on a Fishery. Water Resources Research, Vol. 29, No. 3, p. 575-582.

Klenosky, D. B. (2002). Push and Pull Relationships. Annals of Tourism Research, 29(1), 257260.

Manning, R. 1999. Studies in Outdoor Recreation: Search and Research for Satisfaction. $2^{\text {nd }}$ ed Corvallis: Oregon State University Press

Manning, R., and D. Lime. 2000. Defining and Managing Wilderness Recreation Experiences. Proceedings of the Wilderness Science in a Time of Change Conference. USDA Forest Service Proceedings RMRS-P-15-Vol-4, 13-52.

Manning, R.E. (2003). What to Do About Crowding and Solitude in Parks and Wilderness? A Reply to Stewart and Cole. Journal of Leisure Research , 35 (1), 107-118.

Manning, R.E. (2010). Studies in outdoor recreation: search and research for satisfaction. Corvallis, Oregon, US: Oregon State University Press.

Maundner, M. N., Sibert, J. R., Fonteneau, A., Hampton, J., \& Kleiber, P., Harley, S.J. (2006). Interpreting catch per unit effort data to assess the status of individual stocks and communities. ICES Journal of Marine Sciences, 63(8), 1373-1385.

Miko, D.A., Schramm, H.L., Arey, S.D., Dennis, J.A., \& Mathews, N.E. (1995). Determination of stocking densities for satisfactory put-and-take rainbow trout fisheries. North American Journal of Fisheries Management 15:823-829.

Moldovanyi, A.D., Pierskalla, C.D., and Schuett, M.A. (2005). Reconceptualizing specialization for a fishing subactivity: Is activity and place specialization better understood at the activity or subactivity level? Proceedings paper in 16th Northeastern Recreation Research Symposium. Bolton Landing, NY. March 28-30, 2004.

Navratil, J., Martinsc, S., Picha, K., \& Navratilova, J. (2011). Anglers' choice of fisheries in the Czech Republic. Moravian Geographical Reports, 19(3), 35-47.

Parasuraman, A., Zeithaml, V.A., \& Berry, L.L. (1985). A conceptual model of service quality and its implications for future research. Journal of Marketing, 49, 41-50.

Parasuraman, A., Zeithaml, V.A., \& Berry, L.L. (1988). SERVQUAL: a multi-item scale for measuring consumer perceptions of service quality. Journal of Retailing, 64(1), 12-40.

Parasuraman A., Berry, L. L., \& Zeithaml, V. A. (1991). Refinement and reassessment of the SERVQUAL scale. Journal of Retailing, 69, 420-451. 
Pine, B. J., \& Gilmore, J. H. (1999). The experience economy: work is theatre and every business a stage. Boston, MA: Harvard Business School Press.

Radomski, P. J., G. C. Grant, P. C. Jacobson, and M. F. Cook. 2001. Visions for recreational fishing regulations. Fisheries 26(5):7-18.

Rosenberger, R. S., Collins, A. R., \& Svetlik, J. B. (2005). Private provision of a public good: Willingness to pay for privately stocked trout. Society and Natural Resources. 18:75-87.

Sasser, W. E., Olsen, R.P., and Wyckoff, D.D. (1978), Management of Service Operations: Text and Cases, Boston: Allyn \& Bacon.

Schomaker, J. 1984. Writing Quantifiable River Recreation Management Objectives. Proceedings of the 1984 National River Recreation Symposium, 249-253.

Vaske, J. and D. Whittaker. 2004. Normative Appricts to Natural Resources, Society and Natural Resources: A Summary of Knowledge. Jefferson, MO: Modern Litho, 283-294

Vaske, J., D. Whittaker, B. Shelby, and M. Manfredo. 2000. Indicators and Standards: Developing Definitions of Quality. Wildlife Viewing: A Management Handbook. Corvallis: Oregon State University Press, 143-71.

Wagar, J. A. 1964. The Carrying Capacity of Wild Lands for Recreation. Forest Science Monograph7. Washington, DC: Society of American Foresters.

Whittaker, D., and B. Shelby. 1992. Developing Good Standards: Criteria, Characteristics, and Sources. Defining Wilderness QualityL The Role of Standards in Wilderness Management-A Workshop of Proceedings. USDA Forest Service General Technical Report PNW-305, 6-12

Yoon, Y., \& Uysal, M. (2005). an examination of the effects of motivation and satisfaction on destination loyalty: a structural mode. Tourism Management, 26, 45-56. 